\title{
EFFECT OF FATIGUE ON TORSIONAL FAILURE OF NICKEL-TITANIUM CONTROLLED MEMORY INTRUMENTS
}

\author{
by \\ Les Campbell \\ DDS, University of Alberta 1991 \\ A THESIS SUBMITTED IN PARTIAL FULFILLMENT OF \\ THE REQUIREMENTS FOR THE DEGREE OF \\ MASTER OF SCIENCE \\ in \\ THE FACULTY OF GRADUATE AND POSTDOCTORAL STUDIES \\ (Craniofacial Science)
}

THE UNIVERSITY OF BRITISH COLUMBIA

(Vancouver)

August 2013

(C) Les Campbell, 2013 


\section{Abstract}

Introduction: This study was undertaken to understand how fatigue affects the torsional properties of both traditional nickel-titanium (NiTi) and nickel-titanium controlled memory (CM) files. Methods: Typhoon (TYP) 25.04 and 40.04 rotary files, in both NiTi and CM, were tested using a three-point bending apparatus to obtain the mean number of cycles to failure (mNCF). New files were precycled to four conditions (i.e., $0 \%, 25 \%, 50 \%$, and $75 \%$ of the $\mathrm{mNCF}$ ) before torsional resistance tests were performed. Each file was exposed to torsional stress until failure, and at that point the torque and distortion angles were measured. The fracture surface of each fragment was examined with a scanning electron microscope. Results: The TYP CM files yielded a seven-fold improvement in mNCF over the TYP NiTi files $(P \leq 0.05)$. In both file sizes there was no difference in torque between the $\mathrm{CM}$ files and the conventional Ni-Ti files $(P>0.05)$. The torque of the size 40.04 files was significantly higher than the torque of the size $25 / .04$ files $(P \leq$ 0.05). In the 40.04 TYP files group, the $75 \%$ precycling group had a significantly lower torque to failure than the no precycling group $(P \leq 0.05)$. The CM files of both sizes had significantly higher distortion angles than the Ni-Ti files of both sizes $(P \leq$ 0.05). The 40.04 TYP CM files that were not precycled showed a significantly higher distortion angle than the precycled groups. The fractured files in the precycling groups showed the typical pattern of torsional failure. Conclusions: Cyclic fatigue has an effect on torsional fracture resistance of TYP and TYP CM files on size 40.04. 
TYP CM files displayed a similar torque value to TYP files but rotated a greater angle before fracture in both preloading and no preloading groups. 


\section{Preface}

This thesis is an original, unpublished, and independent work by the author, L. Campbell. None of the text of the dissertation is taken directly from previously published or collaborative articles.

The author was responsible for all parts of the research, including the fatigue testing, the torque testing and the data gathered from such tests. Dr. Ya Shen and Dr. Markus Haapasalo provided the three-point bending apparatus used for the cyclic fatigue testing portion of this experimentation. Both Dr. Haapasalo and Dr. Shen provided invaluable guidance throughout the process. The torsion tests were conducted by myself at the calibration department of D\&S Dental in Tennessee.

Dr. Ya Shen and Zhejun Wang performed statistical analysis of the research. Dr. Markus Haapasalo made significant contributions to the manuscript and was a reviewer of the final draft. Overall, Dr. Shen and Dr. Haapasalo each made a 20\% contribution to the work. 


\section{Table of Contents}

Abstract

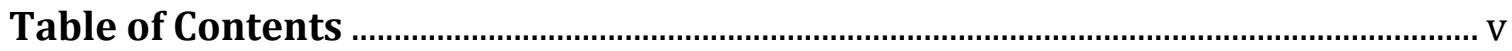

List of Tables ..........................................................................................................................

List of Figures ……............................................................................................................. viii

List of Abbreviations ......................................................................................................... $\mathrm{x}$

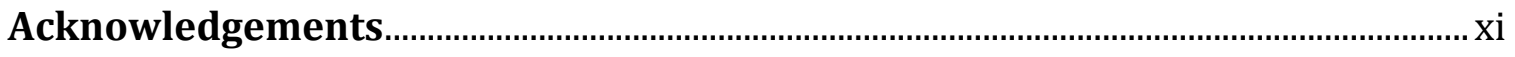

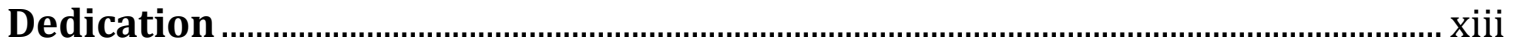

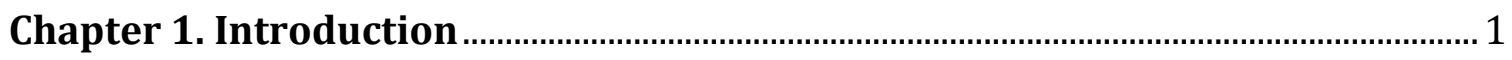

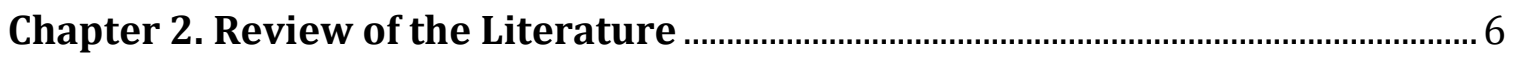

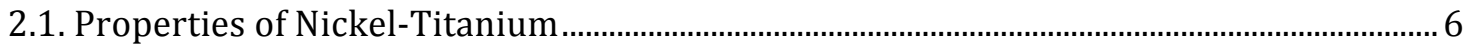

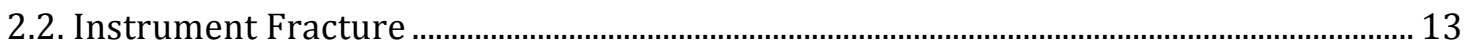

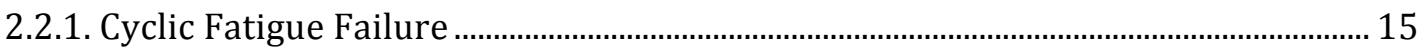

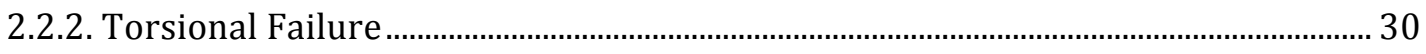

2.3. Fractographic Examination …………………………………………………………………... 32

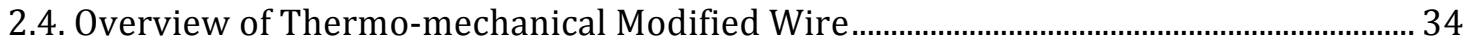

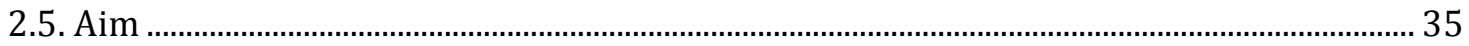

Chapter 3. Hypothesis …….................................................................................. 36

Chapter 4. Material and Methods …………………….......................................... 37 
4.1. Specimen Section

4.2. Method to Cyclically Fatigue Files

4.3. Method to determine angle of deflection and radius ............................................................. 41

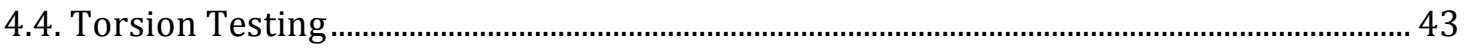

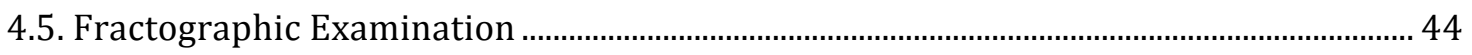

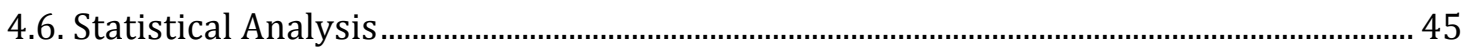

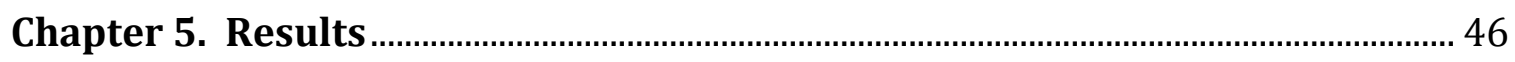

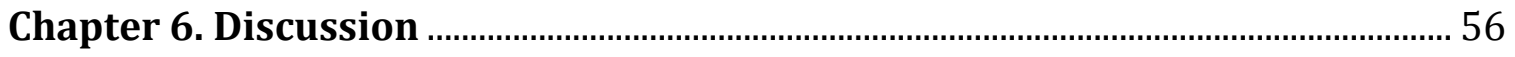

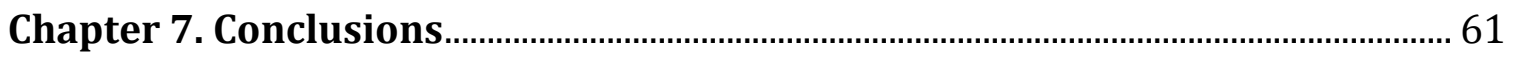

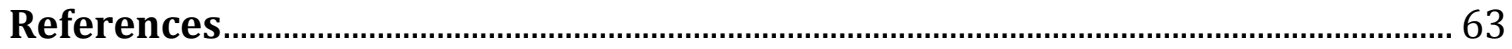




\section{List of Tables}

Table 5.1 The number of revolutions until fracture of Typhoon NiTi and CM files at a $46^{\circ}$ curvature with a $9.5 \mathrm{~mm}$ radius in water conditions.........................47

Table 5.2 (a) Resistance to torque of Typhoon NiTi and CM files after cyclic precycling of the $\mathrm{mNCF}$

Table 5.2 (b) Resistance to torque of 40.04 Typhoon NiTi and CM files after cyclic precycling of the mNCF.

Table 5.3 Mean cyclic fatigue life. .50 


\section{List of Figures}

Figure 2.1. Cuboidal nature of the austenite phase

Figure 2.2. Example of crystal structure of the deformed, detwinned martensite

phase.

Figure 2.3. Differential scanning calorimetry for TYP and TYP-CM rotary endodontic

files. 12

Figure 2.4. Diagrammatic representation of typical failure zones found in cyclical

fatigue failure.

Figure 2.5. Demonstration of the angle of root curvature and the radius of root

curvature. 19

Figure 2.6. Example of curved tube method of testing cyclical fatigue.......................... 20

Figure 2.7. Example of grooved block and rod................................................................ 22

Figure 2.8. Example of the "V" cut into the block to limit random movement of the

file as it rotates 23

Figure 2.9. Example of inclined plane method of testing cyclical fatigue....................... 25

Figure 2.10. Example of the trajectory of a file while engaging an inclined plane..... 26

Figure 2.11. Example of 3-point bending apparatus.

Figure 2.12. Typical examples fractographic images from fractured files. Torsional failure and cyclical fatigue failure 33

Figure 4.1. Demonstration of a three-point bending apparatus. 38

Figure 4.2. Demonstration of a CM file in the three-point bending apparatus. ........... 39

Figure 4.3. CM file being exposed to cyclic fatigue in a water environment................ 40 
Figure 4.4. Drawing the arc prior to measurement. ............................................................. 41

Figure 4.5. Calculation of radius and curvature angle..................................................... 42

Figure 4.6. Removal of a file handle prior to a torsion test. .............................................. 43

Figure 5.1. A photomicrograph of a fracture surface ....................................................... 52

Figure 5.2. Demonstration of conventional NiTi before and after outlining of dimpled

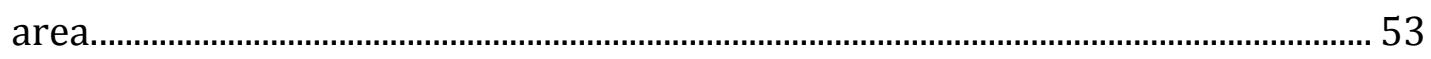

Figure 5.3. 40.04 NiTi dimpled area demonstration .................................................... 54

Figure 5.4. Demonstration of 40.04 CM dimpled area................................................... 55 


\section{List of Abbreviations}

Af- Austenite finish temperature

As- Austenite start temperature

CM- Controlled Memory Wire

ISO- International Organization for Standardization

Mf- Martensite finish temperature

mNCF- Mean number of cycles to failure

Ms- Martensite start temperature

NiTi- Nickel-titanium

SE- Super-elasticity

TYP- Typhoon rotary endodontic files

TYP CM- Typhoon controlled-memory rotary endodontic files 


\section{Acknowledgements}

I would like to express that without Dr. Ya Shen, this project could not have been completed. To her I have the deepest appreciation, and I have often thought that her words were few yet her influence was tremendous. It would be difficult to overstate her impact on the endodontic program and its students. I would also like to express my deepest appreciation for Dr. Markus Haapasalo, who with his support and guidance has broadened my understanding of endodontics. I feel very fortunate to have Drs. Shen and Haapasalo at UBC during my residency, and for involving me in research activities since my first year in the program.

I would like to thank Dr. Jeff Coil for not only his work on my committee, but also as a mentor and program director. Clinically your guidance was very significant, and I learned much from your patience and your clear direction in patient treatment. Your questions in the classroom caused me much to ponder over, and thus a better understanding of this wonderful discipline.

Contributions in the clinic by Luciana Nakayama, Francisco Briseno, Lois Bermudez and Shauna Catalano improved patient care and brightened each day.

I would also like to thank Dr. Jolanta Aleksejuniene for being on my committee and the input she had into making this successful.

My appreciation goes out to Zhejun Wang and Dr. Ya Shen for their insight and contribution to the statistics in this study.

My gratitude is given to my friends and peers in the SJC community, Anna 
Belogurova, Ilksen Icen and his sense of humor, Amber Perreca, Stefan Honisch and Dawood Al-Masslawi, who each helped me to complete this work in ways they are not aware of. My appreciation is given to Anna who changed and shaped my thoughts in many ways and was a role model for hard work.

This research was generously supported by the donation of materials by Clinician's Choice Dental. Contributions made by the Canadian Academy of Endodontics, the American Association of Endodontics and the S. Wah Leung endowment were greatly appreciated and facilitated the completion of this research. 


\section{Dedication}

To my family that supported me on this adventure ...... 


\section{Chapter 1. Introduction}

To prepare endodontic canals for irrigation delivery and eventually obturation, they must be properly cleaned and shaped. While cleaning refers to the removal of all organic debris, shaping implies the creation of a unique shape for every root canal, directly related not only to the length but also to the position and curvature of each individual root and root canal (Schilder, 1974; Testarelli et al., 2011). While shaping has traditionally been done with stainless steel files, it has been recognized that stainless steel has limitations in root canal instrumentation, primarily because this material is stiff and tends to cause procedural errors such as zips and ledges in curved canals (Bishop \& Dummer, 1997; Kim et al., 2012). It was evident that a suitable alternative for use in endodontics was needed to stainless steel.

Walia (1988) introduced nickel-titanium (NiTi) to endodontics, which has led to a completely new way of thinking about and performing canal preparation. Nickel-titanium has distinct advantages; most importantly, it is far more flexible than stainless steel as it demonstrates the property of super-elasticity (SE). This allows files made from NiTi to flex more before exceeding the material's elastic limit than files made from stainless-steel (Walia et al., 1988), particularly as increased file sizes are used. More specifically, super-elasticity allows for up to $8 \%$ deformation due to strain and will still revert to its original shape, whereas for stainless-steel the value is less than $1 \%$. Esposito described nickel-titanium files as more effective in 
maintaining the original canal path of curved root canals, particularly when the apical preparation was enlarged beyond size 30 (Esposito \& Cunningham, 1995). Furthermore, NiTi files seem to be safer because of the reduced amount of transportation towards danger areas as compared to stainless steel instruments due to their flexibility (Chan \& Cheung, 1996). Moreover, the importance of NiTi has been underlined by clinically applicable research. For example, endodontic therapy performed with nickel-titanium hand instruments led to a better prognosis (Pettiette et al., 2001) and lower procedural errors with a higher success rate as measured one-year after treatment (Cheung \& Liu, 2009) when compared to teeth treated with stainless-steel instruments.

However, nickel-titanium and stainless steel both share the unfortunate trait of the possibility of fracture, which can be sudden and without warning. This can occur with brand-new instruments or in the hands of a seasoned practitioner (Pruett et al., 1997; Zuolo \& Walton, 1997; Arens et al., 2003). Factors contributing to instrument failure have being attributed to operator error, instrumentation techniques, instrument design, instrument size, radius of curvature, surface condition and rotation rate. (Pruett et al., 1997; Parashos et al., 2004; Cheung et al., 2005; Shen et al., 2009b; Gao et al., 2010). However, Sattapan (2000a) was the first to describe the fracture mechanisms of NiTi rotary endodontic files and by doing so he deepened our initial understanding of the types of failure these files may exhibit. Sattapan reported that file failure occurring during routine clinical use could be attributed to either torsional fracture or flexural fatigue. He identified torsional 
fracture as the cause of slightly over half of the separated files he studied (Sattapan et al., 2000a). However, other authors have attributed the majority of file failures to cyclical fatigue (Haïkel et al., 1999; Shen et al., 2006). Torsional fracture can be described as what happens when the tip of the file binds in the canal, while the remainder of the file continues to rotate. Fatigue failure, also known as cyclical fatigue, occurs in curved canals where one side of the instrument undergoes compression and the other side tension (Kramkowski \& Bahcall, 2009). For a better understanding of the fracture mechanism, several factors must be considered; however simulation of all these factors in laboratory conditions is difficult (Pruett et al., 1997; Sattapan et al., 2000a; Gao et al., 2010; Wycoff and Berzins, 2012; Lopes et al., 2013). Thus, factors contributing to file fracture are frequently considered separately.

Manufacturers have attempted to improve the safety and reliability of rotary endodontic files by developing new manufacturing processes, (Larsen et al., 2009; Alapati et al., 2009a; Gambarini et al., 2011; Ye \& Gao, 2012) or by introducing new alloys with superior mechanical properties (Testarelli et al., 2011). An example of this is M-wire (Sportswire LLC, Langley, OK) which has been introduced with a proprietary thermomechanical manufacturing process (Alapati et al., 2009a). Efforts to improve the performance of files have generally focused on the metallurgical and mechanical properties of the file itself. However, factors that the operator may introduce, such as cyclical fatigue and torsional stresses and their effects on each other, have received only limited attention in the literature (Kim et al., 2012). 
Recently, a modification of nickel-titanium wire through a propriety thermomechanical treatment has been introduced to the market and is known as controlled-memory wire (Typhoon CM; Clinician's Choice Dental Products, New Milford, CT). The manufacturer claims that files made from CM wire have 300\% greater fatigue and more than double the torsional resistance than conventional files made from nickel-titanium (2010). Heat treatment (thermal processing) is one of the most fundamental approaches for adjusting the transition temperatures of NiTi alloys and affecting the fatigue resistance of NiTi endodontic files (Gambarini et al., 2011; Shen et al., 2011b; Gutmann and Gao, 2012; Zhou et al., 2012; Lopes et al., 2013; Shen et al., 2013b). Several novel thermomechanical processing and manufacturing technologies have been developed to optimize the microstructure of NiTi alloys. However, details of the methods used are proprietary. Introduced recently, NiTi rotary instruments made from a NiTi wire subjected to thermomechanical processing (CM wire) have been introduced into the market (Typhoon CM; Clinician's Choice Dental Products, New Milford, CT). The CM wire technology has made the NiTi instruments more resistant to cyclic fatigue than conventional super-elastic NiTi instruments (Bishop and Dummer, 1997; Shen et al., 2011a; 2012). It is expected that thermomechanically treated NiTi instruments maintain the same torsional properties as conventional SE NiTi instruments. It is likely that torsional and fatigue forces happen simultaneously during root canal preparation, but little information is available on the subject. Furthermore, it is unknown how a previous exposure to fatigue may affect the properties of a thermomechanically treated wire such as CM files. Therefore, the aim of this study was to 
evaluate the effect of cyclic fatigue on torsional failure of Typhoon $\mathrm{Ni}$-Ti and $\mathrm{CM}$ instruments. 


\section{Chapter 2. Review of the Literature}

\subsection{Properties of Nickel-Titanium}

The endodontic community has increasingly embraced nickel-titanium (NiTi) files since they were first introduced to the discipline (Walia et al., 1988). However, it is well-recognized in the community that these files can separate during use with little or no warning (Walia et al., 1988; Sattapan et al., 2000a; Arens et al., 2003). A better understanding of this exotic metal may shed some light on its failure mechanisms.

Nickel-titanium does not conform to normal behavior as described in metallurgy, and is therefore described as an exotic metal. Endodontic NiTi files are largely made from nearly equal atomic ratios of nickel and titanium, being described as $54-57.5 \%$ wt \% nickel (Walia et al., 1988; Esposito and Cunningham, 1995; Zinelis et al., 2010). This alloy can exist in various forms, differentiated by the shape of the crystal structures or phases. The phases are generally known as the austenite (Figure 2.1), martensite (Figure 2.2) and the R-phase. The R-phase is a short-lasting transition phase occurring between the austenitic and martensitic phases; the " $\mathrm{R}$ " represents the so-called rhomboidal shape the lattice assumes during this brief period. Both stress and temperature are influencing factors that determine which phase the metal will exist in at any one time. 


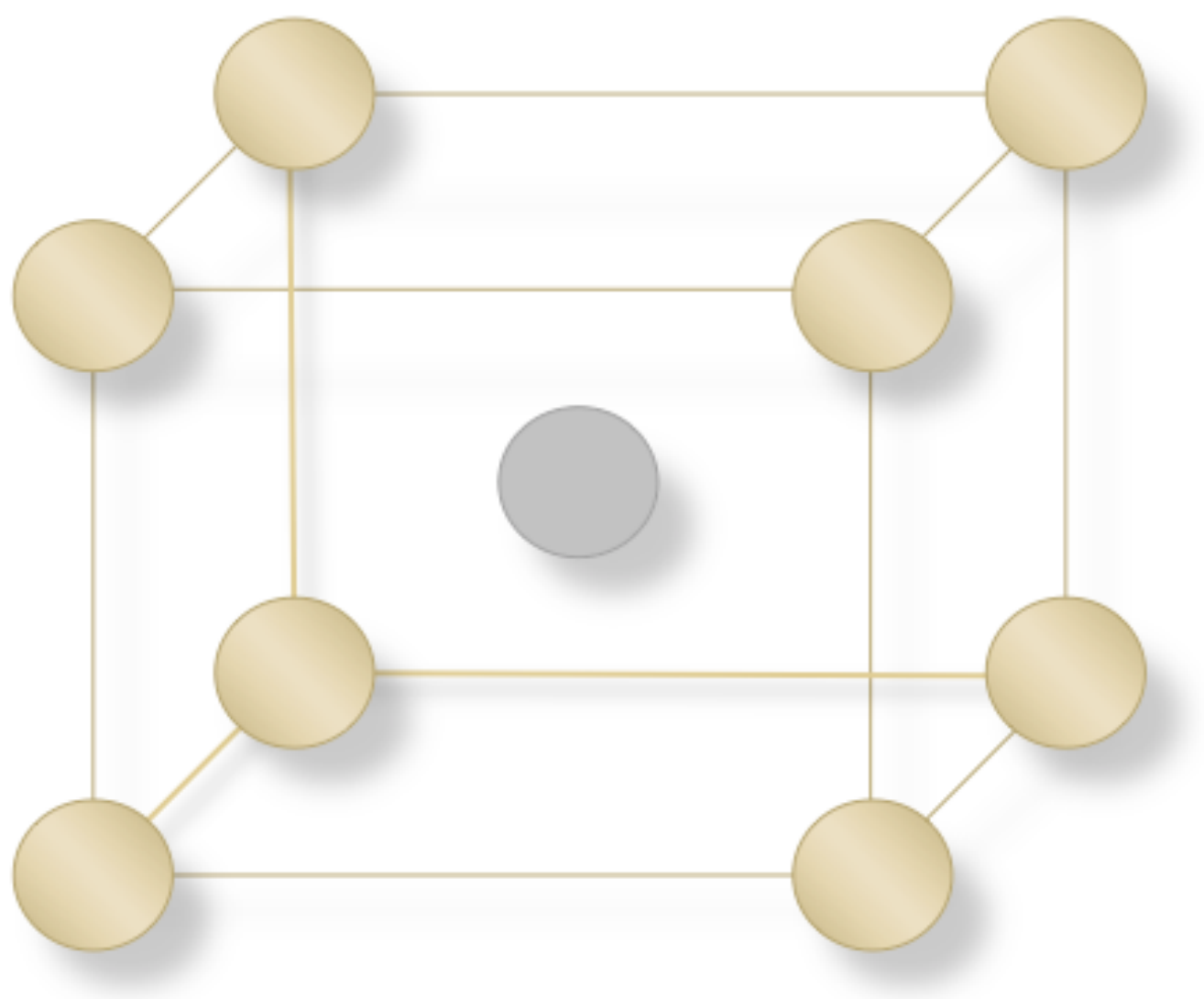

Figure 2.1. Cuboidal nature of the austenite phase. 


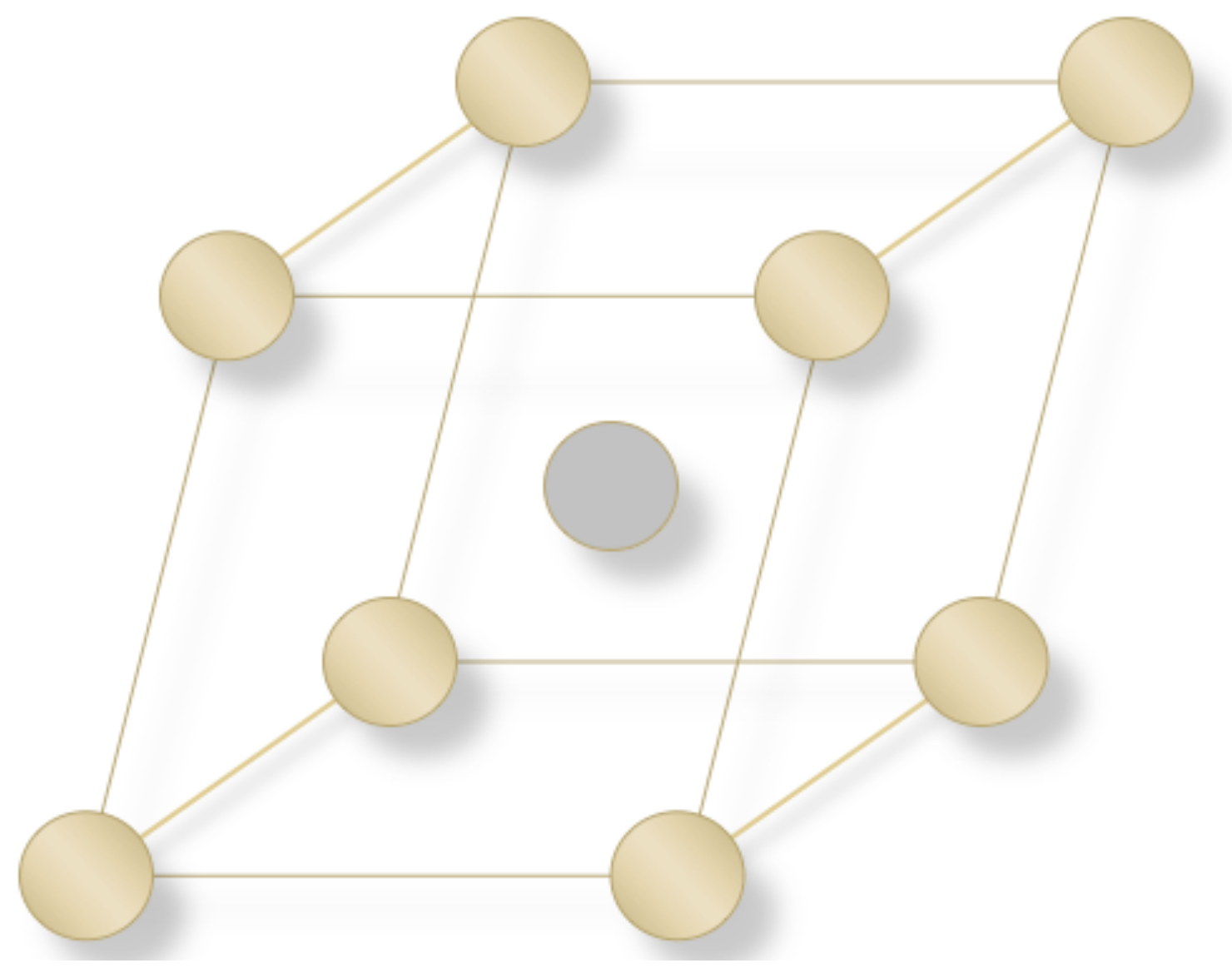

Figure 2.2. Example of crystal structure of the deformed, detwinned martensite phase. 
The special features of NiTi are superelasticity (SE) and shape memory, exhibited by the changing dimensions of these crystal phases within the metal. SE occurs upon loading, but before deformation; if the stress introduced to the metal is released, the metal will return to its original shape. Other metals such as copperaluminum, nickel-niobium and gold-cadmium have also shown SE behavior; however nickel-titanium is considered to be the most biocompatible (Buehler and Wang, 1968; Thompson, 2001). In 1963, W.F. Buehler, while working with metals for the Naval Ordinance Laboratory, described the shape-memory effect of "titanium-nickel" (Buehler et al., 1963). He demonstrated that when heat was applied to deformed metal, sudden dimensional changes would occur so that the metal would regain its original shape. This metal was called Nitinol" from "ni" for nickel, "ti" for titanium and "nol" for the Naval Ordinance Laboratory.

The phenomena of SE and shape memory can be attributed to the particular phase present within the metal. Austenite, also known as the B2 cubic crystal structure or the parent-phase, is a body-centered cuboidal crystal that is apparent in $\mathrm{Ni}$-Ti wire at higher temperatures. It is hard, stable at room temperature and is the usual phase seen in conventional Ni-Ti rotary instruments prior to clinical use. (See Figure 2.1). As the temperature of the metal rises there is a phase shift within nickel-titanium toward austenite. Should the metal cool or when strain is applied, the nickel-titanium will enter the martensitic phase. This "daughter phase" is also 
described as having a monoclinic B19' structure. (See Figure 2.2). It is present in trace amounts at room temperature in most rotary nickel-titanium instruments. Martensite has two phases attributed to it, namely twinned and detwinned. As the temperature cools, martensite enters a twinned crystal structure. Once stress is placed upon the twinned martensite, it will become detwinned. As mentioned, it is the relationship between austenite, and twinned and detwinned martensite that gives rise to the phenomenon known as shape memory (Thompson, 2001).

When heat is applied during the martensitic phase, or when a stress is released before the plastic deformation limit is reached, the martensitic nickeltitanium will enter a transformation period and eventually assume an austenitic structure. When this happens the lattice will reassume a body-centered cube lattice and the metal will exhibit shape memory. The temperature at which this process begins is the austenite transformation start temperature (As). Once the heat has completed the transformation of the metal, the austenite transformation finish temperature (Af) will have been reached. The converse is also true. When nickeltitanium is in the austenite phase and is cooled, it will begin the transformation to martensite. This is known as the martensite transformation start temperature (Ms). Once a sufficient cooling temperature has been reached the metal will revert back to martensite, known as the martensite transformation finish temperature (Mf). In its martensitic form, the metal is soft, elastic and ductile. 
Brantley showed that he could measure the transformation temperatures using a process called Differential Scanning Calorimetry (DSC) (Brantley et al., 2002). This was important because he showed that Profile and Lightspeed Ni-Ti rotary instruments were in the austenite phase at room temperature and therefore demonstrated super-elastic behavior during clinical use. Conventional Typhoon NiTi also rests primarily in the austenite phase at room temperatures, however the controlled-memory variant does not (Shen et al., 2011b). DSC curves of TYP-CM have shown transition temperatures to be well above room temperatures, prompting the metal to reside in the martensitic phase. This ductile phase is largely responsible for the lack of memory, or more specifically the reduction in superelasticity (Figure 2.3). The upper line in Figure 2.3 represents heating of the metal, whilst the lower line represents the cooling curve. Generally speaking, the austenite phase lies to the right of the "bumps" on the curve and martensite to the left. In Figure 2.3 it is apparent that the transition temperatures for TYP-CM are higher than TYP, which explains the different phase states of these two rotary files, and that at room temperatures a significant portion of the TYP-CM file will reside in the martensitic form (Shen et al., 2011b). 

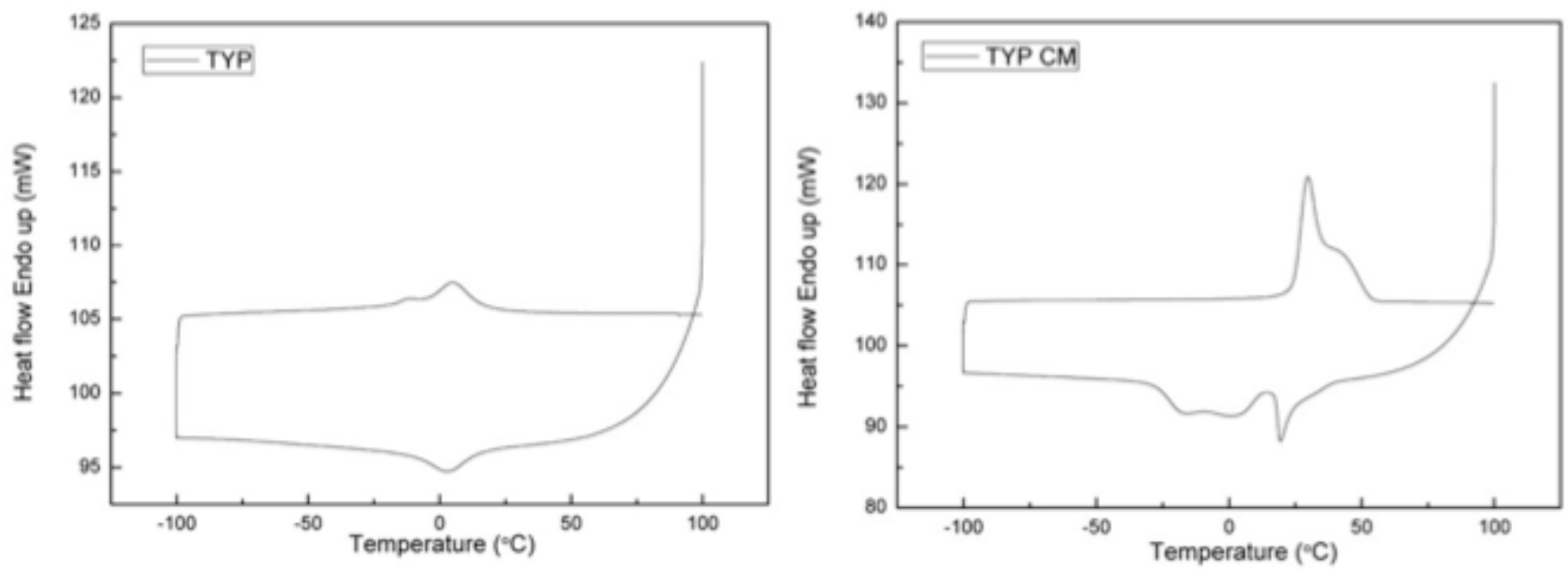

Figure 2.3. Differential scanning calorimetry for TYP and TYP-CM rotary endodontic files.

Reprinted from Journal of Endodontics: Shen et al, "Metallurgical Characterization of Controlled Memory Wire Nickel-Titanium Rotary Instruments”, 2011, 37:1566-1571, Copyright, with permission from Elsevier.

Nickel-titanium is an exotic metal, which does not conform to normal metallurgical properties. There is a complex interaction between the different phases of the material that make it useful to industry. Stress-induced or temperature-induced transformations between austenite and martensite are responsible for shape memory and super-elasticity, and provide the unique properties for this interesting metal. 


\subsection{Instrument Fracture}

The separation of a portion of an endodontic rotary file during instrumentation can be an unexpected and unpleasant situation. It is possible that the separated fragment could prevent proper chemomechanical debridement beyond its location in the canal if it not able to be bypassed or removed. Depending on the pre-operative diagnosis, the canal beyond the fractured instrument may contain a thriving biofilm community, which may decrease the likelihood of a successful endodontic treatment. Fortunately, the incidence of Ni-Ti file separation is low, generally less than 5\% of all treatments (Al-Fouzan, 2003; Parashos et al., 2004; Spili et al., 2005). Parashos attributed $1.5 \%$ of file separations to torsional failure and 3.5\% to cyclical fatigue. Most of the time, the fragment will lodge itself in the apical portion of the canal (Parashos and Messer, 2004), which may prevent adequate debridement of this important area of the canal.

The impact a separated instrument has on the prognosis of a case seems to be limited. A threshold quality and quantity of bacteria cause endodontic diseases, not a separated instrument in and of itself. Similarly, in both stainless-steel and nickel-titanium endodontic files, a separated fragment does not appear to significantly decrease the outcome of the case (Crump and Natkin, 1970; Spili et al., 2005). Spili, who looked at over 8000 cases of instrument fracture, determined a prevalence of $3.3 \%$, with the majority of those separations being attributed to nickel-titanium rather than stainless steel. He examined several variables to 
determine prognosticating factors in cases involving a broken instrument. He found the largest influence on outcome was not whether a fractured instrument remained in the canal, but rather if a case involving a separated instrument was associated with a periapical lesion. Regardless, any potential loss of tooth structure whilst trying to remove the fractured fragment must be weighed into the decision to try to remove it or not (Souter and Messer, 2005).

File separation has been considered as occurring from either of two ways: fatigue failure or torsional (shear stress) failure. Nickel-titanium rotary files are associated with fatigue-failure, while hand files made from stainless steel are more associated with torsional failure (Shen et al., 2009a). However, a more likely scenario is that a complex interaction exists between these two types of failure, and that they occur simultaneously to cause file separation. The details of each mode of separation and their laboratory tests are explored in the next two sections. 


\subsubsection{Cyclic Fatigue Failure}

As a file rotates in a curved canal, it will experience tension and compression within a single rotation. If the file is held in this position for a threshold amount of time, separation will occur due to crack propagation within the metal. There are several laboratory tests used to measure cyclic fatigue; however there is no current International Organization for Standardization (ISO) standard used to measure the fatigue life of rotary endodontic files. This presents a problem to the endodontic profession, as comparing one fatigue study to another is invalid due to the different parameters of each test. Currently, the most important result within any particular fatigue test is how the files rank when compared to each other within the same test. Thus, less emphasis should be placed on comparing results between studies. Additionally, caution should be exercised in the interpretation of the actual value in revolutions per minute or time lapsed before fracture, as the testing methods do not accurately reproduce clinical conditions and the results found clinically may be quite different.

Most of the techniques used to measure fatigue in endodontic files use a static handpiece with a second device that introduces a curve into the rotary endodontic file. Once rotation begins, the time it takes for the file to fracture is then recorded. However, one does not keep the handpiece in a single place during 
instrumentation in a clinical setting. The fatigue life of a file can be considerably extended if the file is moving up and down during instrumentation. It should be noted that this motion has been shown to extend fatigue life to a greater extent in smaller diameter files compared to larger diameter files. (Dederich \& Zakariasen, 1986).

In cyclic fatigue, failure of the file will occur through several stages. The failure will begin with crack initiation. Potential sites for crack initiation are surface defects such as milling grooves created during the manufacturing of the file (Peng et al., 2005). Inclusions, which are defects in the metal commonly containing carbon, can also contribute to a site of crack initiation. The proximity of the inclusion to the surface of the file is important to crack initiation, as inclusions that are further away from the surface of the file are less of a threat to crack initiation (Atkinson \& Shi, 2003). Subsequently, the crack will continue into the next phase, called crack propagation. During the crack propagation phase, the file continues to rotate. As it rotates, the file microscopically opens and closes at the crack initiation site. This can lead to a particular pattern within the file called "fatigue striations" or "beach marks" created by the rapid opening and closing of the crack site (Cheung et al., 2005). Once this progression of successive micro-fractures makes its way through the file, the pieces will suddenly separate. This is known as the "overload zone" (Ounsi et al., 2007) and is typically identified by a dimpled area at some distance away from the crack initiation site seen when the end of the file is examined under a scanning electron microscope (see Figure 2.4). 

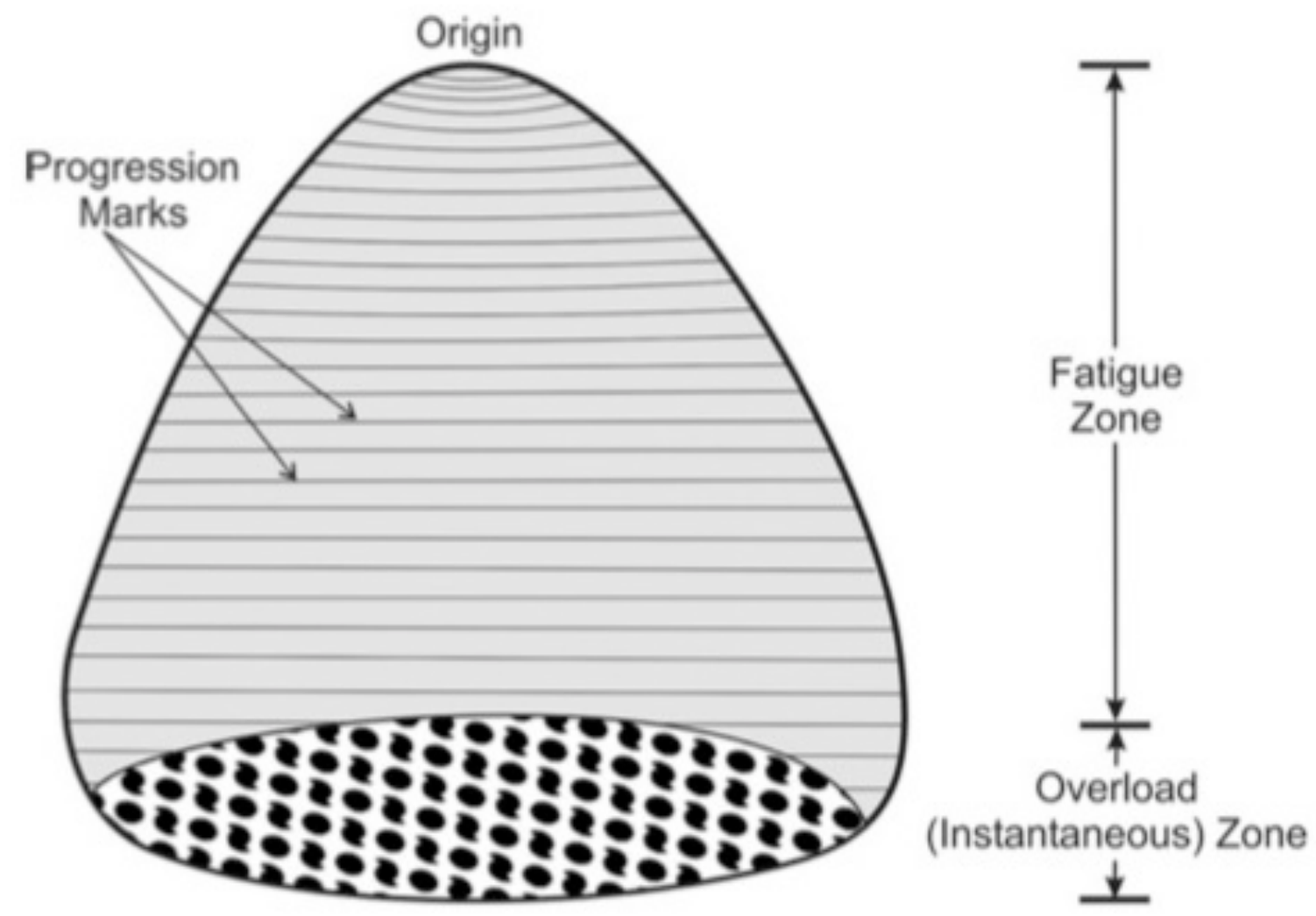

Figure 2.4. Diagrammatic representation of typical failure zones found in cyclical fatigue failure.

Reprinted from Journal of Endodontics: Ounsi et al, "Effect of Clinical Use on the Cyclic Fatigue Resistance of ProTaper Nickel-Titanium Rotary Instruments", 2007, 33:737741, Copyright, with permission from Elsevier. 
The angle at which the file engages the curve has an important impact on the fatigue life of the file. The greater the angle, the quicker the file will fail (Pruett et al., 1997). The measurement of this angle was introduced by Schneider (Schneider, 1971). However, the degree of curvature in the root is only one factor when considering the fatigue life of an instrument. When testing Lightspeed files, Pruett found that angles greater than $30^{\circ}$ led to a significant decrease in fatigue life, but moreover Pruett found that the radius this angle passed through also had a significant effect on fatigue life. As the radius decreased, the fatigue life of the instrument also decreased. His conclusions were that the angle of the root and the radius of the curvature of the root had more effect on file failure than the rotational speed of the instrument (Pruett et al., 1997). In other words, regardless if the angles of root curvature are the same, the radius of the curvature has a significant effect on the cyclical fatigue of rotary instruments (see Figure 2.5).

Methods to measure cyclic fatigue in the laboratory are numerous. Each device is designed to allow rotation of the file while introducing minimal torsional effects. The cylindrical curved tube has been used to introduce an angle into rotary files. They have been made from metal (Pruett et al., 1997; Mize et al., 1998; Yared et al., 1999) or from glass (Anderson et al., 2007; Barbosa et al., 2008), and have been made with a variety of angles of curvature and radii. Ostensibly, the glass offers the benefit of the researcher being able to see the file as it rotates. A diagrammatic representation of the curved tube is offered in Figure 2.6. 

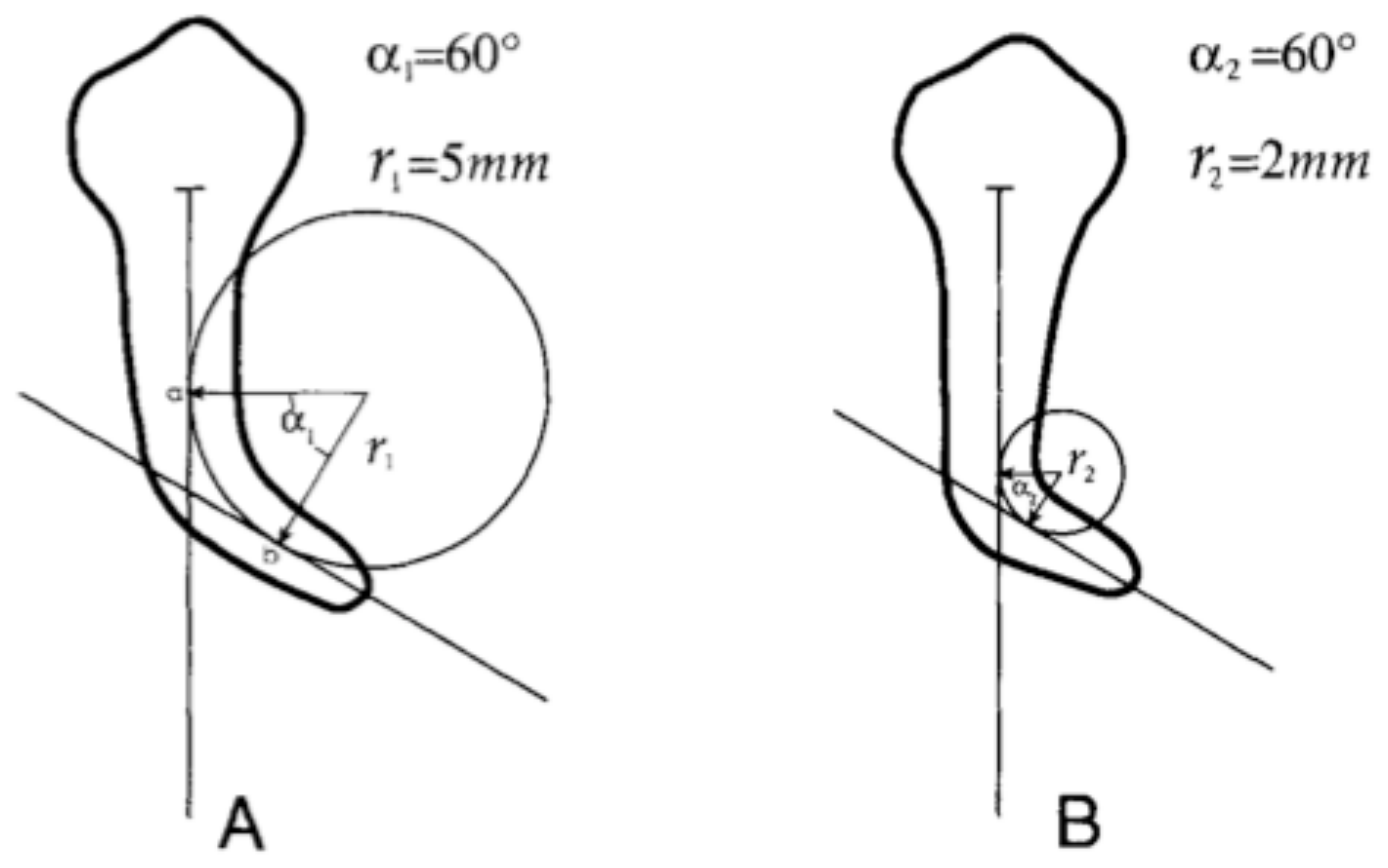

Figure 2.5. Demonstration of the angle of (A) root curvature and (B) the radius of root curvature.

Reprinted from Journal of Endodontics: Pruett et al, "Cyclic Fatigue Testing of NickelTitanium Endodontic Instruments", 1997, 23:77-85, Copyright, with permission from Elsevier. 


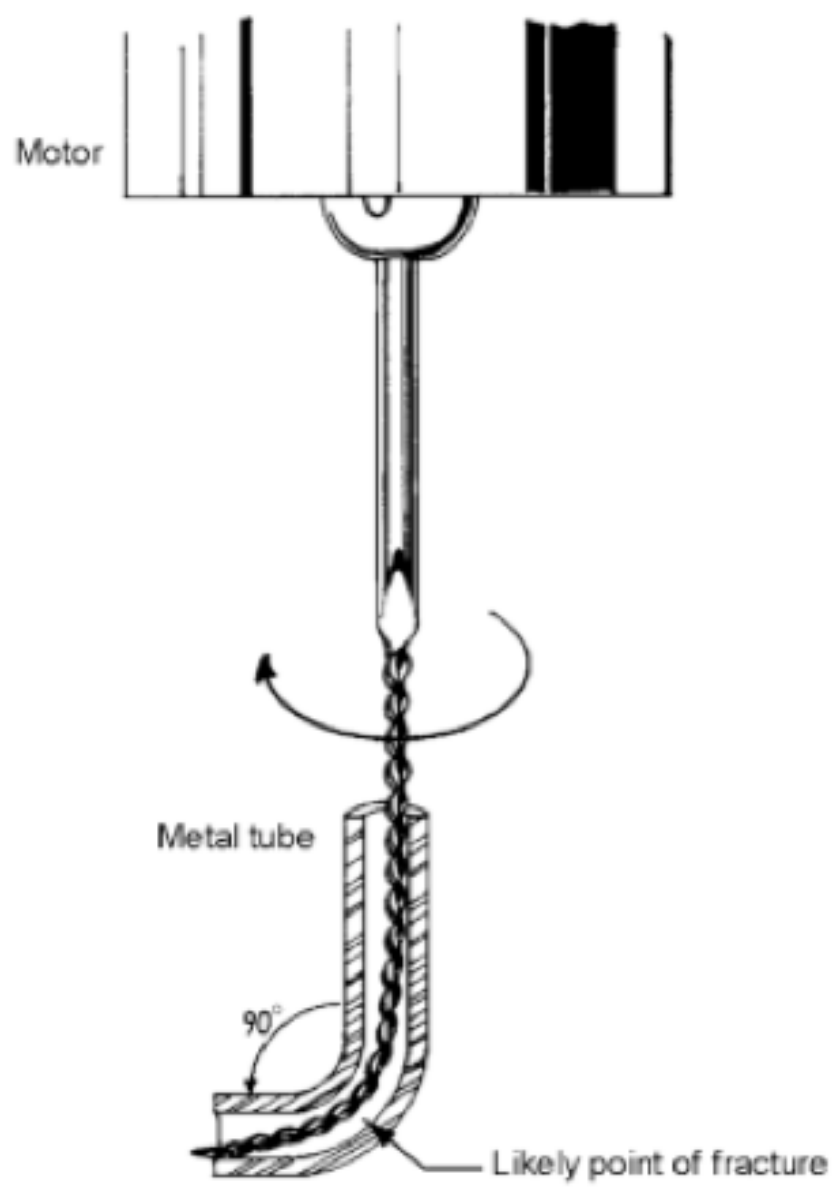

Figure 2.6. Example of curved tube method of testing cyclical fatigue.

Reprinted from Endodontic Topics, Cheung, G., "Instrument Fracture: mechanisms, removal of fragments and clinical outcomes", 2009, 16:1-26, Copyright, with permission from Elsevier. 
The method of using curved tubes to measure cyclic fatigue has some significant design problems. Chiefly, the angle of curvature and the radius of the tube will be slightly different from the file depending on how well the file fits into the tube (Plotino et al., 2009). If the tube is too wide in diameter the files will fit loosely within it. This is a problem, as superelasticity will cause the files to straighten, pushing the file to the outer edges of the tube as the file engages the curve. The result is that smaller tapers will have a different trajectory within the tube when compared to files with larger tapers, and smaller files would be overrepresented in their fatigue life (Cheung, 2009). In other words, the deformed angle and radius of a smaller file will be slightly larger than the larger file within the same tube. This would lead to a type I error within the test. Alternatively, if the tube is too narrow then undesirable torsional forces will be introduced into the cyclical test, as the sides of the file will bind into the tube. A theoretical solution would be to have a series of tapered curved tubes that more closely matches the geometry of the files that are being tested, but with adequate diameter not to cause binding.

An alternate method of cyclically testing files is the grooved block and rod (Figures 2.7 and 2.8). It was first suggested for use by Haïkel who put a "V" shape in the block end to keep the file engaged in a single location within the testing apparatus (Haïkel et al., 1999). 


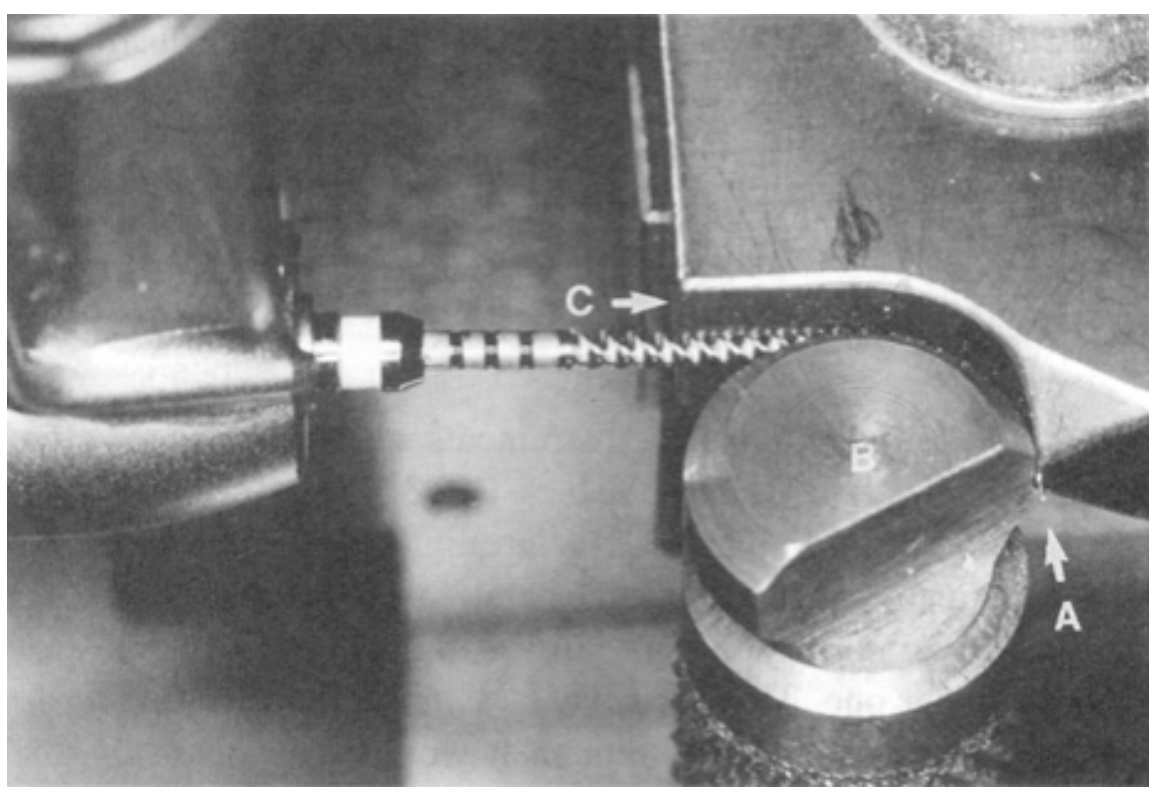

Figure 2.7. Example of grooved block and rod.

Reprinted from Journal of Endodontics, Haïkel et al, "Dynamic and Cyclic Fatigue of Engine-Driven Rotary Nickel-Titanium Endodontic Instruments", 1999, 25:434-440, Copyright, with permission from Elsevier. 


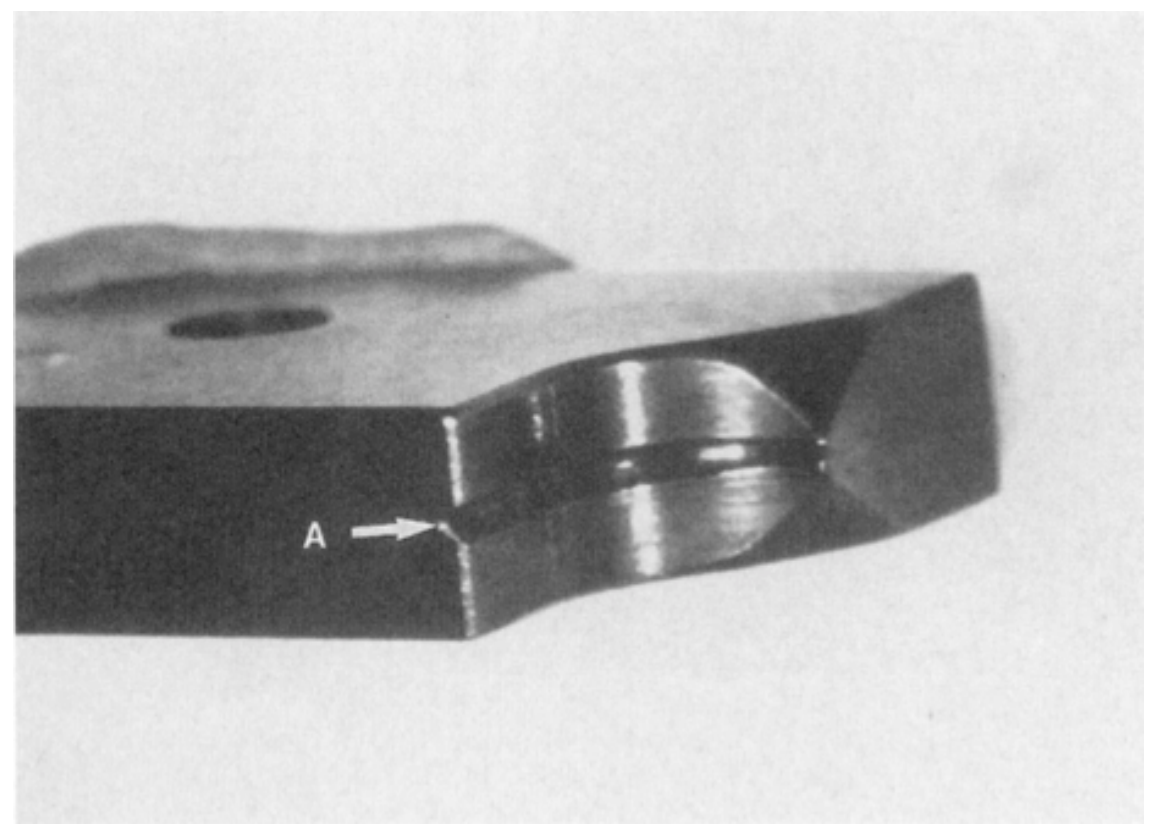

Figure 2.8. Example of the " $\mathrm{V}$ " cut into the block to limit random movement of the file as it rotates (Indicated by the letter "A").

Reprinted from Journal of Endodontics, Haïkel et al, "Dynamic and Cyclic Fatigue of Engine-Driven Rotary Nickel-Titanium Endodontic Instruments", 1999, 25:434-440, Copyright, with permission from Elsevier. 
Notice that in the block the "V" groove is tapered. This addresses some of the problems encountered in the curved tube model; however unless the file is fully engaged in the apparatus, it could still suffer from different angles and radii within the same test. In this apparatus, the file is engaged throughout its length against the rod or the block. Thus, unless lubricated, slight torsional resistance along with frictional heat could lead to confounding variables within the test. The authors recognized this and addressed it by streaming cold air over the rod and block. It is unknown how frictional heat would affect the phase transformation during this test, as the possibility of a phase transformation toward austenite could occur along with a loss of ductility of the file during the test.

A third way of introducing a curvature to a file during a cyclic fatigue test is the inclined plane (Figure 2.9), or an inclined metal block to which the file would engage, introduced by Li (Li et al., 2002). With a smooth inclined plane, it may be difficult to prevent the file from "walking off" the incline once rotation begins, or in other words it is difficult to keep the file within its long axis. In the following study a groove was placed into the inclined plane to keep the file in place (Kitchens et al., 2007). Plotino points out that in both studies only Schneider's method of calculating angulation was taken into account, without considering the larger impact that the radius of the curvature has on fatigue (Plotino et al., 2009). Additionally, this method, similarly as the previously two described methods, is subject to variance within the test due to the bending properties of the files that are used in the test. The angulation and radius are very challenging to consistently achieve with the inclined plane while using instruments of various tip sizes and taper. 


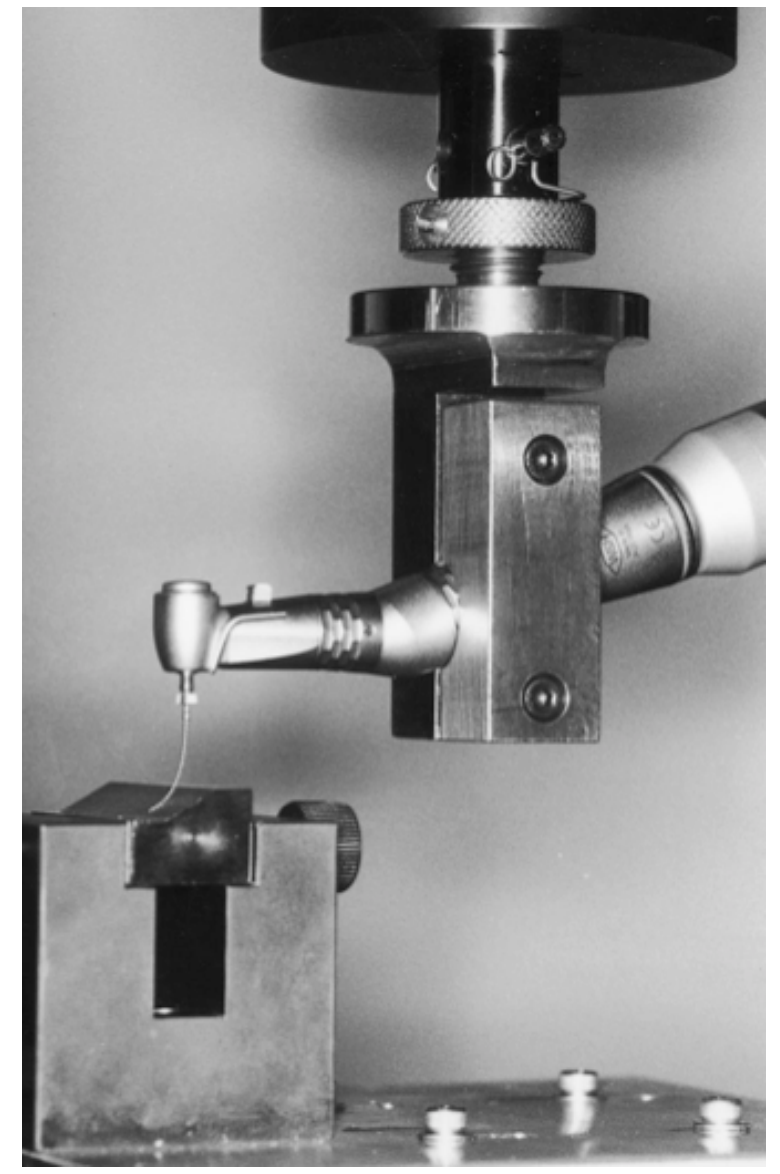

Figure 2.9. Example of inclined plane method of testing cyclical fatigue.

Reprinted from Journal of Endodontics, Li et al, "Cyclic Fatigue of Endodontic Nickel Titanium Rotary Instruments: Static and Dynamic Tests", 2002, 28:448-451, Copyright, with permission from Elsevier. 


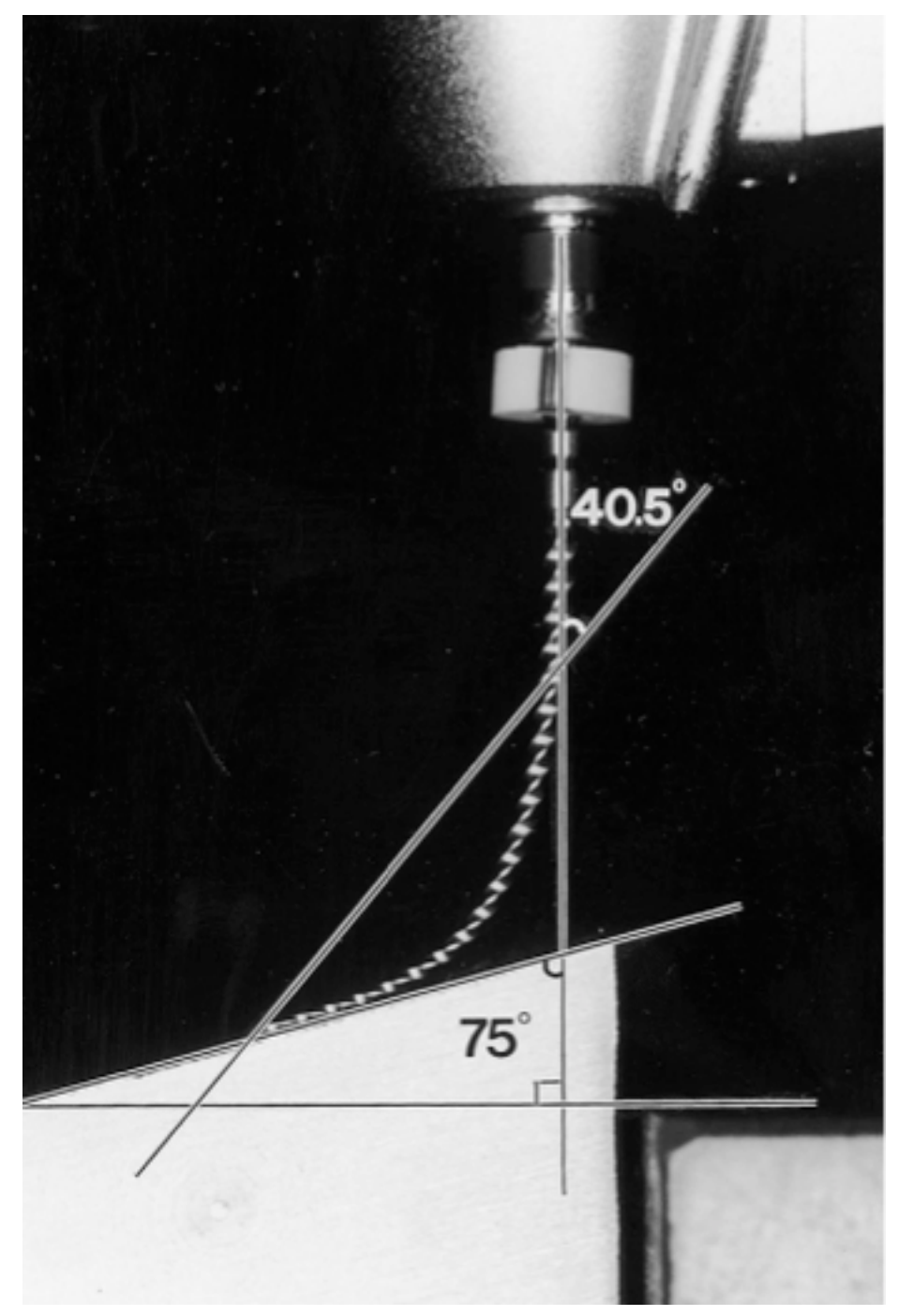

Figure 2.10. Example of the trajectory of a file while engaging an inclined plane.

Reprinted from Journal of Endodontics, Li et al, "Cyclic Fatigue of Endodontic Nickel Titanium Rotary Instruments: Static and Dynamic Tests", 2002, 28:448-451, Copyright, with permission from Elsevier. 
In the previous cyclic fatigue devices discussed, the concept of how well an instrument fits into the apparatus has not yet been elucidated in the literature. Cheung attempted to improve some of these apparatus and the problems they presented by introducing a three-point pin bending apparatus (Cheung and Darvell, 2007). The apparatus consisted of three hardened pins emanating from three vertically stacked small flat steel plates that could slide over each other in a horizontal direction. This allowed for an adjustment of the curvature of the instrument that could be customized for each test. Another benefit of this apparatus is that for testing it could be immersed in liquid. From a metallurgical engineering standpoint, Cheung claims that the three-point bending apparatus more accurately represents a circular curvature introduced into the file, and this allows for a more accurate mathematical calculation of fatigue life (determination of the fatigue life when compared to the strain amplitude) (Cheung, 2009). However, as the file is rotating the longitudinal axis must be kept constant and not allowed to wander from its concentric rotation. In this model, concentricity along the long axis of the file is still subject to variability, and any deviation in the file from its long axis will affect the accuracy of such mathematical calculations. Similarly to other models, a groove is cut into the apparatus to prevent deviation from the long axis of the rotating file; in this case it is placed where the file is in contact with the lowest pin.

Bhagabati recently introduced a custom-made cyclic fatigue device, which he claims is able to precisely reproduce a radius and curvature angle of interest. The 
settings are accomplished through the use of a computer-aided milling device. The apparatus needs closer scrutiny; however the idea of using computers to calculate a more precise angle and radius introduced to a file is intriguing (Bhagabati et al., 2012).

As one can see from the previous descriptions, there are potential problems with each type of cyclic fatigue test. This is likely the reason for such a delay in an ISO standard for the fatigue testing of rotary endodontic files. It would be to the enhancement of the scientific literature if cyclic fatigue tests were to a standard, and therefore could be comparable to each other. 


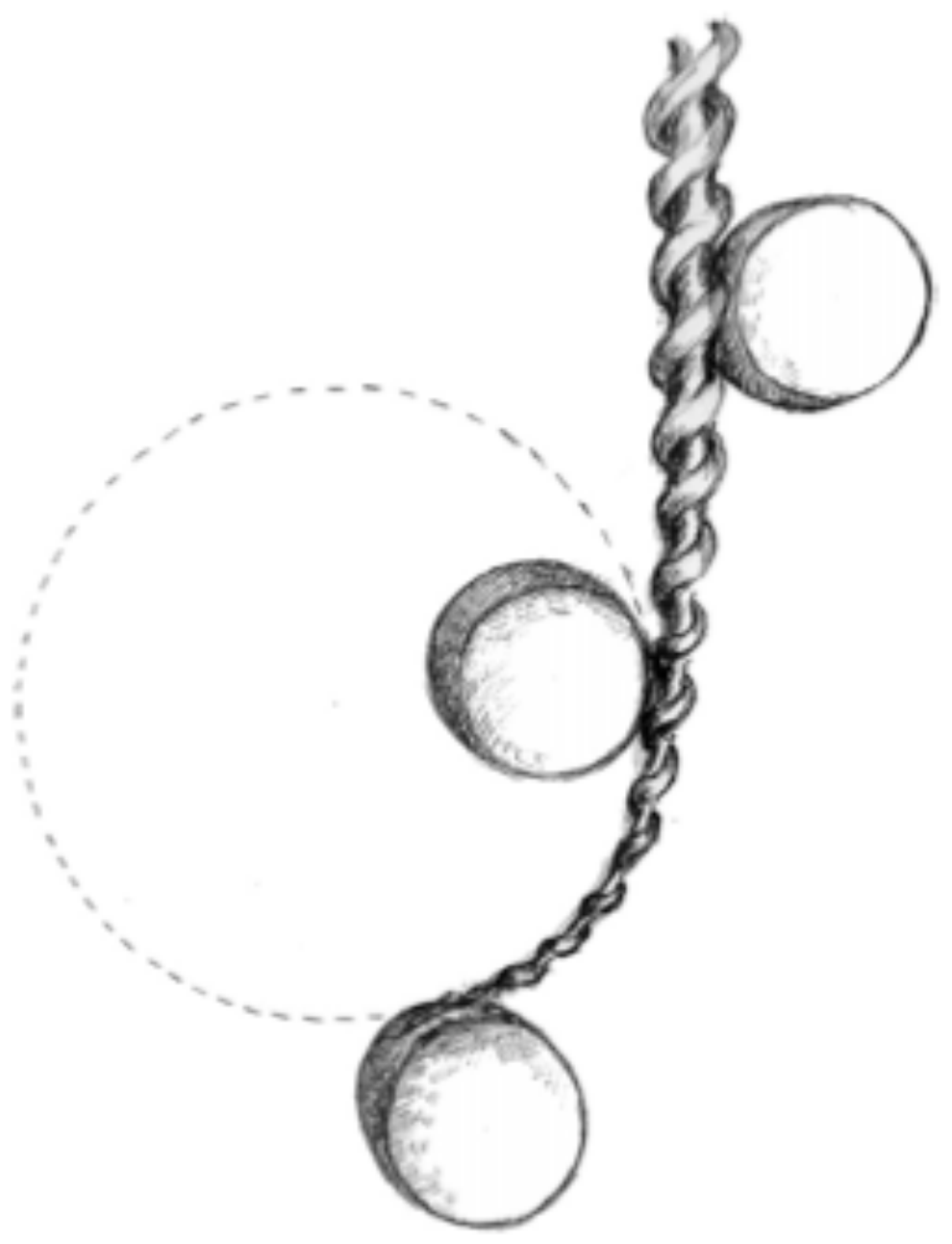

Figure 2.11. Example of 3-point bending apparatus.

Reprinted from Journal of Endodontics, Plotino et al, "A Review of Cyclic Fatigue Testing of Nickel-Titanium Rotary Instruments", 2009, 35:1469-1476, Copyright, with permission from Elsevier. 


\subsubsection{Torsional Failure}

While cyclic fatigue will happen in a curved canal, file failure due to torque can happen in both a curved or straight canal. Torsional failure occurs when the tip binds within the canal and the shaft of the file continues to rotate. A stress is then placed within the metal and the file can separate. A stress-strain curve applies to the examination of torsional failure with endodontic rotary files. As stress is continuously applied until the elastic limit of the metal is reached, the material will then arrive at its yield point. If stress is continued to be applied beyond the yield point, deformation of the metal will begin to occur. During this phase, plastic hardening occurs until the ultimate strength of the metal is reached and separation will occur shortly afterwards, albeit typically at a lower stress than that which was needed to reach the ultimate strength of the material (Yum et al., 2011).

To the benefit of the discipline, there is a standard for torque testing of endodontic rotary files (ISO3630-1, 2008). This test is performed with an apparatus called a torsiometer. The last $3 \mathrm{~mm}$ of a file is clamped within the soft brass jaws of a torsiometer, from D0 to D3. A motor rotates the file at a standard of two cycles per minute until failure. A sensor records the torque applied and the rotational angle the file passed through until separation.

The features of endodontic rotary files that contribute to their resistance to torsional failure are varied. Taper, tip size, and diameter of canal have been implicated in torsional failure, with the bigger tip sizes and larger tapers being able 
to withstand higher torque values (Sattapan et al., 2000b; Yared, 2004). However, other authors have identified features other than size of the file. Reducing the pitch of the file or in other words increasing the amount of cutting edges per unit length and also increasing the cross sectional area but not the core area of the file are suggested to increase torque values (Baek et al., 2011). The authors also suggested that rectangular cross sections are more resistant to torque than triangular sections. Moreover, other authors suggest the cross sectional dimensions of the file are significantly more important than tip size or taper with regard to withstanding torsional forces (Zhang et al., 2010).

An interesting study discussed how the viscosity of lubricants affected torsion of files that were used in canals that contained mixtures of peroxide, surfactant and polyethylene glycol, with distilled water and sodium hypochlorite. They found that regardless of the lubricant used, no significant difference in torque values were measured after 12 times of repeated use (Siqueira et al., 2012).

An interesting variation on measuring torque is called dynamic torque or torsional fatigue. The latter name found in the literature may be confused with cyclical fatigue, which as explained has an entirely different failure mechanism. Dynamic torque is the repetitious rotation of the file to a predetermined angle or torque to a sub-threshold failure level; a single rotation to failure, as specified in the ISO, is not a sufficient means to replicate clinical conditions (Cheung, 2009; Park et al., 2010). One study found that larger defection angles led to significantly greater 
failures in a dynamic torque model (Best et al., 2004), and another found that files with the same cross sectional shape had different results when tested in dynamic torque. They proposed this difference was due to the differences of the manufacturing processes of the different files tested (Park et al., 2010). Ostensibly, when one deviates from a uniform method of testing such as the ISO torque test, the results become impossible to compare between tests.

\subsection{Fractographic Examination}

Fractographic examination is the viewing and description of the broken endodontic file from end of the file in the longitudinal axis (Cheung et al., 2005). It is accomplished with the aid of the scanning electron microscope (Figure 2.12). Features of fractography with regard to cyclic fatigue have been described in section 2.2.1. Fractographic features with cyclic fatigue may involve more than one location of crack origin and progress along the file with small striations as the fatigue process continues. Torsional failures have a markedly different pattern, characterized by swirl marks on the end of the file with the dimpled area characteristically located toward the center of the file.

Sattapan described some of the differences between cyclic fatigue and torsional failures as being identified by the lateral appearance of the file (Sattapan et al., 2000a). He described torsional failures as being identified by file unwinding, and fatigue failures as having the absence of this identifier; however Cheung and others 
have shown that unwinding of the file may not occur yet the fractographic appearance of the file still suggests a torsional failure (Cheung et al., 2005). Furthermore, Cheung described the majority of failures occur as a fatigue failure rather than a torsional failure.
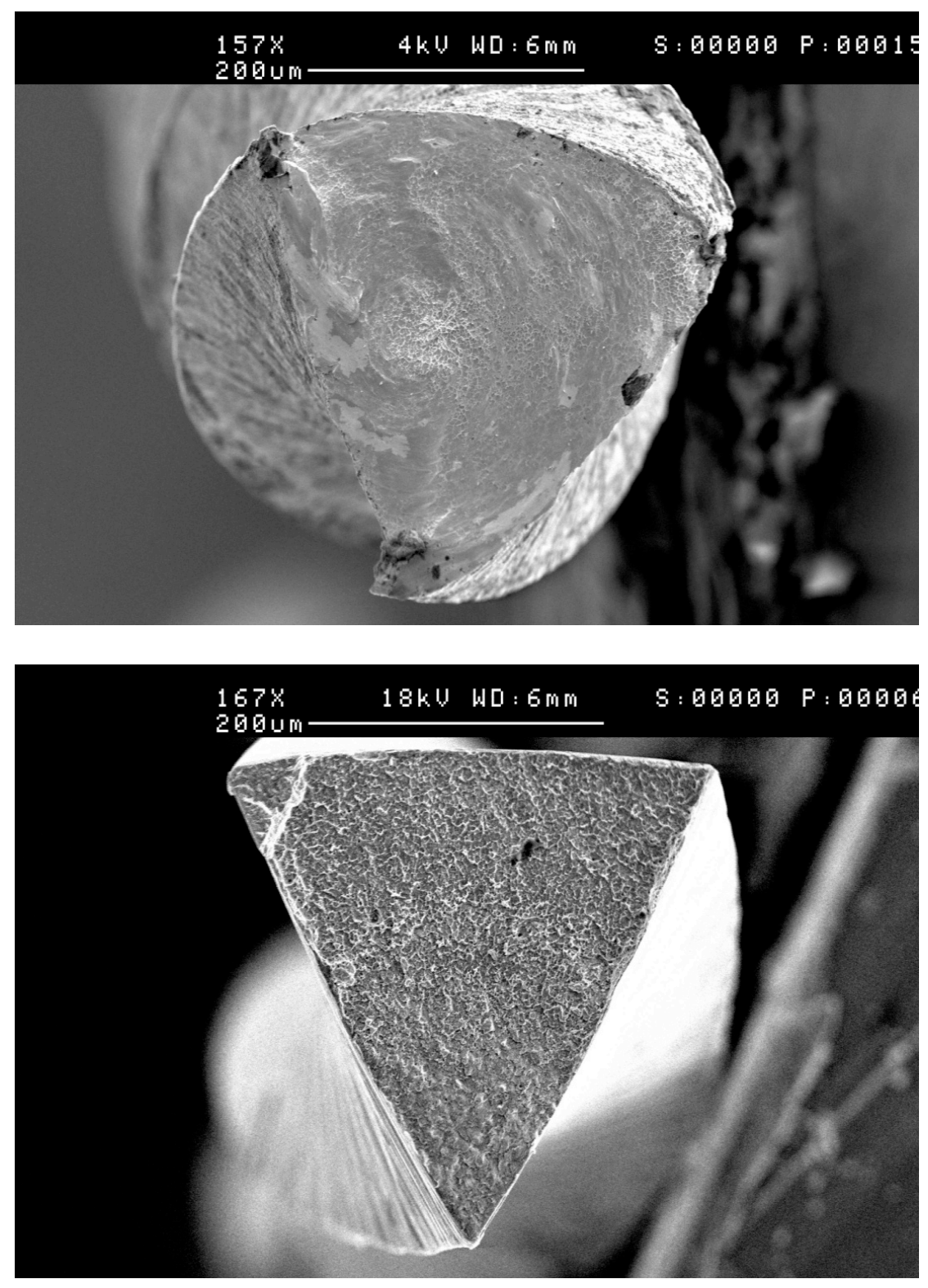

Figure 2.12. Typical examples fractographic images from fractured files. Torsional failure (above) and cyclical fatigue failure (below) are demonstrated. 


\subsection{Overview of Thermo-mechanical Modified Wire}

Manufacturers of earlier generations of rotary Ni-Ti files concentrated on the geometry of the file, either laterally such as the pitch and helical angle, or the geometry in cross section. The current trend of attempts to improve the performance of these instruments is to manipulate the metallurgy, particularly with heat treatments, the details of which are proprietary. Interestingly, the crystal structure of martensite is better able to delay the onset of fatigue, as this may be attributed to its twinned atomic state (Shen et al., 2011a; 2011b). If a file has the simultaneous phases of austenite and martensite, it will have a better fatigue resistance than a file that exists in an austenite phase, as crack propagation occurs more rapidly in austenite than martensite (McKelvey and Ritchie, 1999). Indeed this has been shown in newly introduced thermo-mechanically modified rotary files (Alapati et al., 2009a; Shen et al., 2011b; Peters et al., 2012; Shen et al., 2013a). As mentioned, the ideal temperature to provide heat treatment is proprietary, however an interesting study showed heat treatments from $430-440^{\circ} \mathrm{C}$ were able to significantly increase the fatigue resistance of Ni-Ti rotary files, while instruments exposed to temperatures above and below this level showed a lower level of fatigue resistance (Zinelis et al., 2007). Alapati found he could manipulate the Af temperature of ProFile rotary instruments (Dentsply Tulsa Dental, Tulsa, OK) after heat treatments (Alapati et al., 2009b). Conventional NiTi files have an austenite structure at room or body temperatures, while CM wire displays higher Af than conventional NiTi (Shen et al., 2011b) and as a result a greater amount of the 
instrument rests in the martensite phase at these same temperatures (Alapati et al., 2009a; Ye and Gao, 2012; Zhou et al., 2012). Shen has reported CM wire as having a lower critical stress for the reorientation to martensite than other superelastic wires. Additionally, CM wire has a lower ultimate tensile strength but a significantly higher maximum strain than superelastic wires. These properties lead to a greater degree of flexibility of CM wires which contrasts sharply with conventional NiTi wire (Shen et al., 2013b).

The physical properties and phase state of CM wires have an effect on cyclical fatigue, however environment also plays a role. Shen et al., found that when CM wire was immersed in a water bath, the fatigue resistance of this material was even greater. A possible explanation for this is the liquid media may be acting as a heat sink during the fatigue process (Shen et al., 2011a). Repeated autoclave cycles do not appear to effect the maximum torque values of CM wire (Casper et al., 2011), but it is unknown if these repeated autoclave cycles cause changes in fatigue resistance or in the phase composition of the files.

\subsection{Aim}

The aim of this study is to provide a detailed understanding of the effects of cyclical fatigue on the torsional failure values of conventional nickel-titanium Typhoon and Typhoon CM instruments. 


\section{Chapter 3. Hypothesis}

There is no influence of previous exposure of cyclical fatigue on the torsional failure of conventional nickel-titanium files or controlled memory Typhoon files. 


\section{Chapter 4. Material and Methods}

The fatigue testing protocol has been described previously and was reproduced throughout the experimental period (Shen et al., 2011a; 2012).

\subsection{Specimen Section}

Typhoon $^{\text {TM }}$ (Clinician's Choice Dental Products, New Milford CT) rotary endodontic files were selected for this study because the same cross sectional design was found in both the NiTi and CM files. File sizes 25.04 and 40.04 were selected for use in both file types to show any potential differences in behavior of the different file sizes or types.

\subsection{Method to Cyclically Fatigue Files}

NiTi rotary instruments of Typhoon and Typhoon CM were subjected to rotational bending at the curvature of $46^{\circ}$ with a $9.5-\mathrm{mm}$ radius in deionized water at the temperature of $23^{\circ} \pm 2^{\circ} \mathrm{C}$. Only a 16 - $\mathrm{mm}$ length from the tip of the instrument was immersed in the liquid medium during the test to avoid galvanic action between the instrument and its handle (Shen et al., 2012). NiTi and CM files, in both 25.04 and 40.04 were fatigued to failure and the mean for each file size and type was determined. Subsequently, each file size and type was exposed to $25 \%, 50 \%$, and 
$75 \%$ of their respective mean fatigue life while immersed. Both the mean number of cycles to fatigue (mNCF) and time were recorded. A three point bending apparatus was used to cyclically preload the files, similar to the one demonstrated in Figure 4.1 and Figure 4.2.

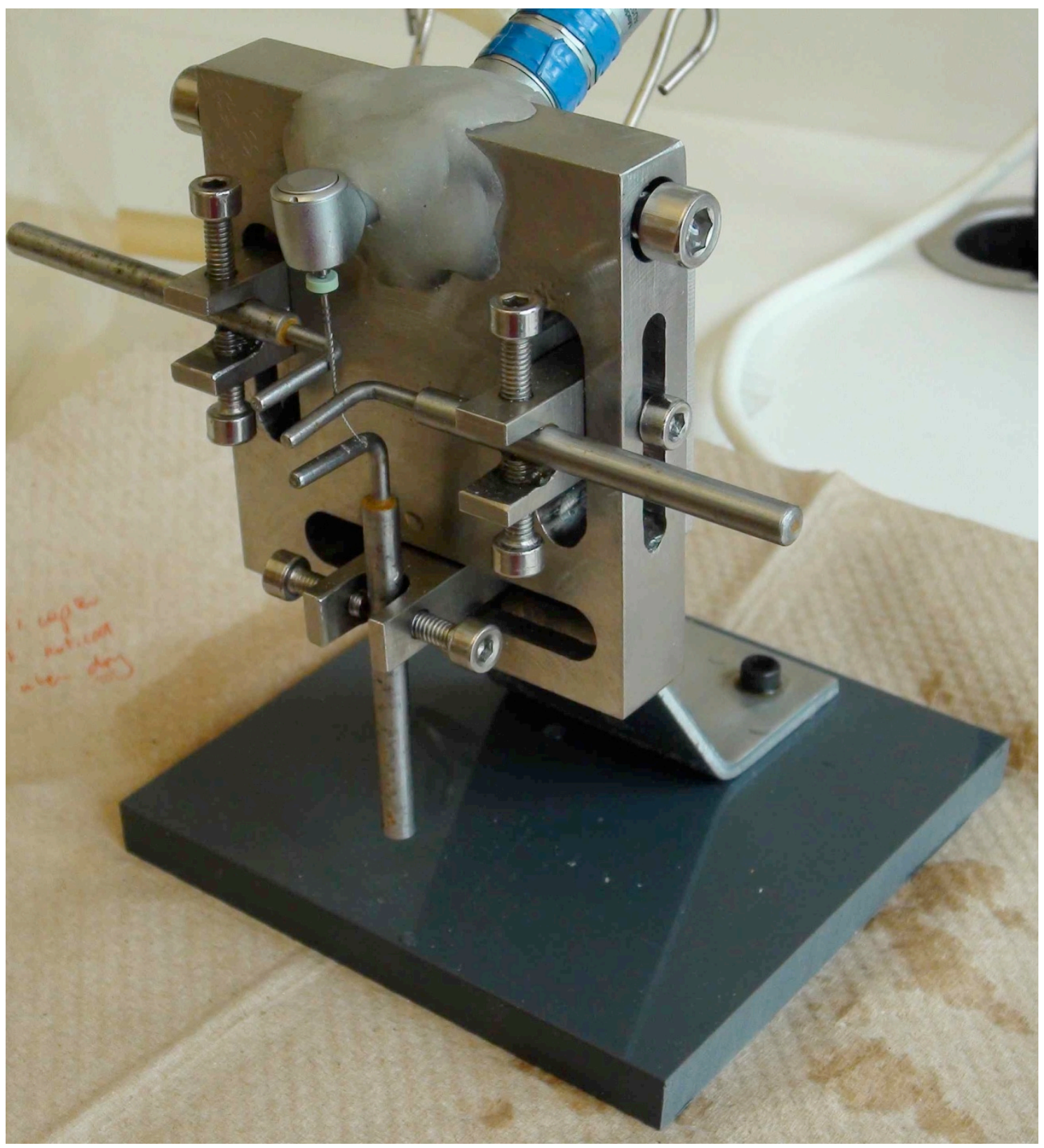

Figure 4.1. Demonstration of a three-point bending apparatus. 


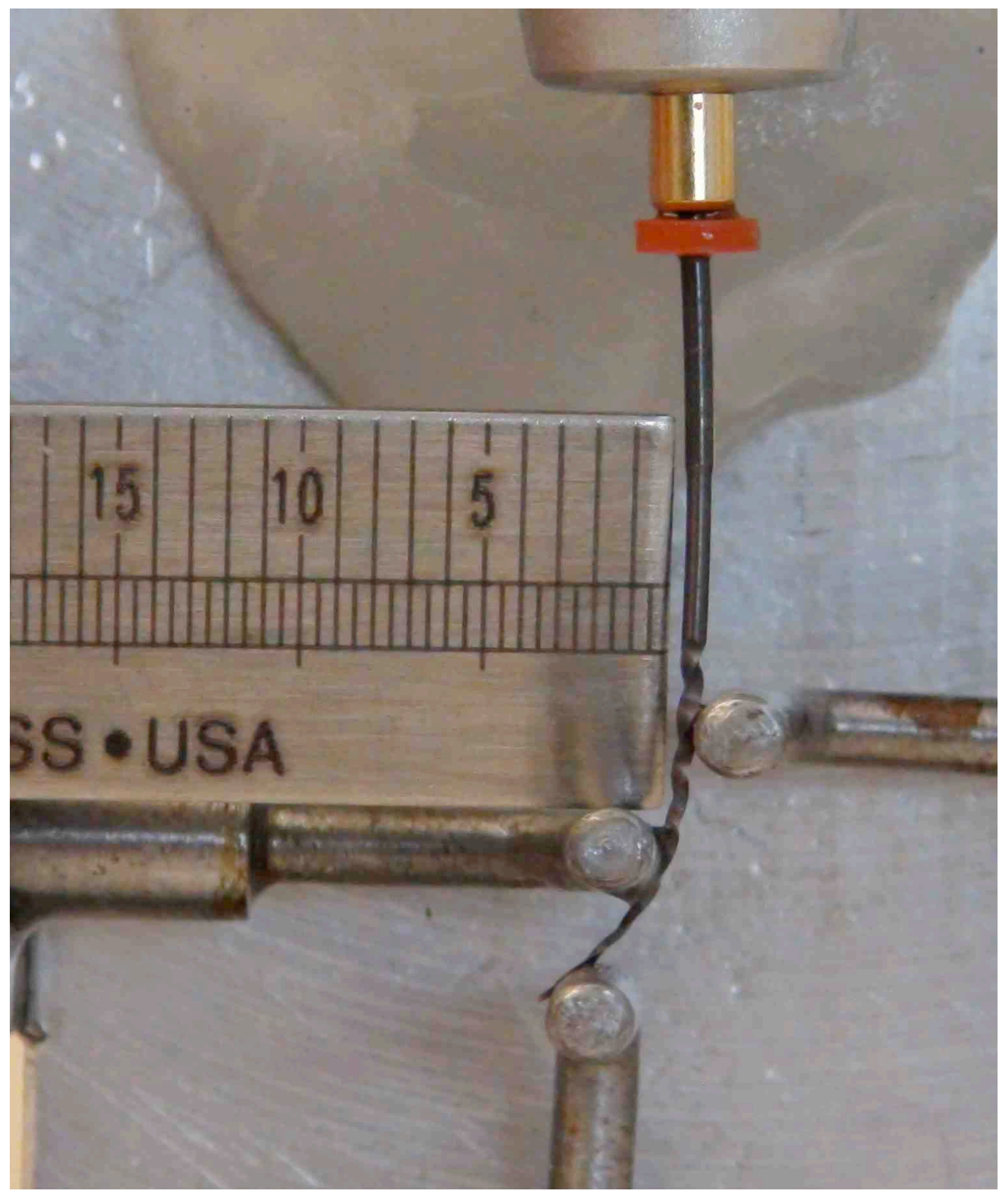

Figure 4.2. Demonstration of a CM file in the three-point bending apparatus. 
In order to have the file placed at the correct position, it was necessary to locate the handpiece carefully within a rectangular notch at the top of the threepoint bending apparatus (see Figure 4.1). This was held in place with Triad Light Curing Material (Dentsply International, York, PA). The top two pins on the apparatus were sitting passively against the file, while the majority of the curvature of the file was introduced as a result of the location of the lowest pin. There was a small notch cut into the lowest pin to keep the file centered in its longitudinal axis while rotating. An ongoing test is demonstrated in Figure 4.3.

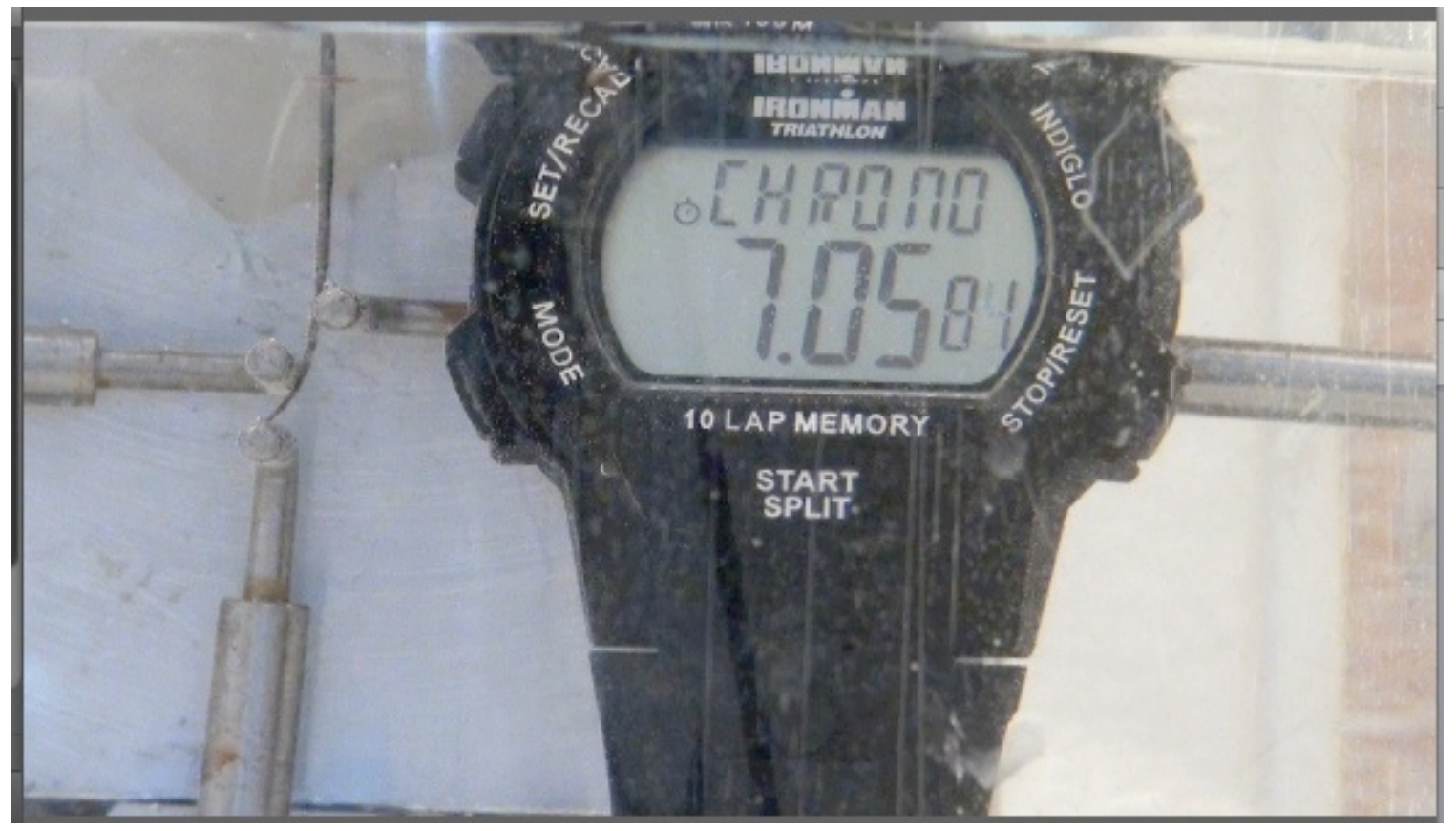

Figure 4.3. CM file being exposed to cyclic fatigue in a water environment. 


\subsection{Method to determine angle of deflection and radius}

In order to determine the angle of file deflection and distance of the radius, the software program "Image)" was used (National Institutes of Health, Bethesda, Maryland). The determination of the angle of deflection and radius was accomplished by creating an arc and then subsequently measuring it as shown in Figure 4.4.

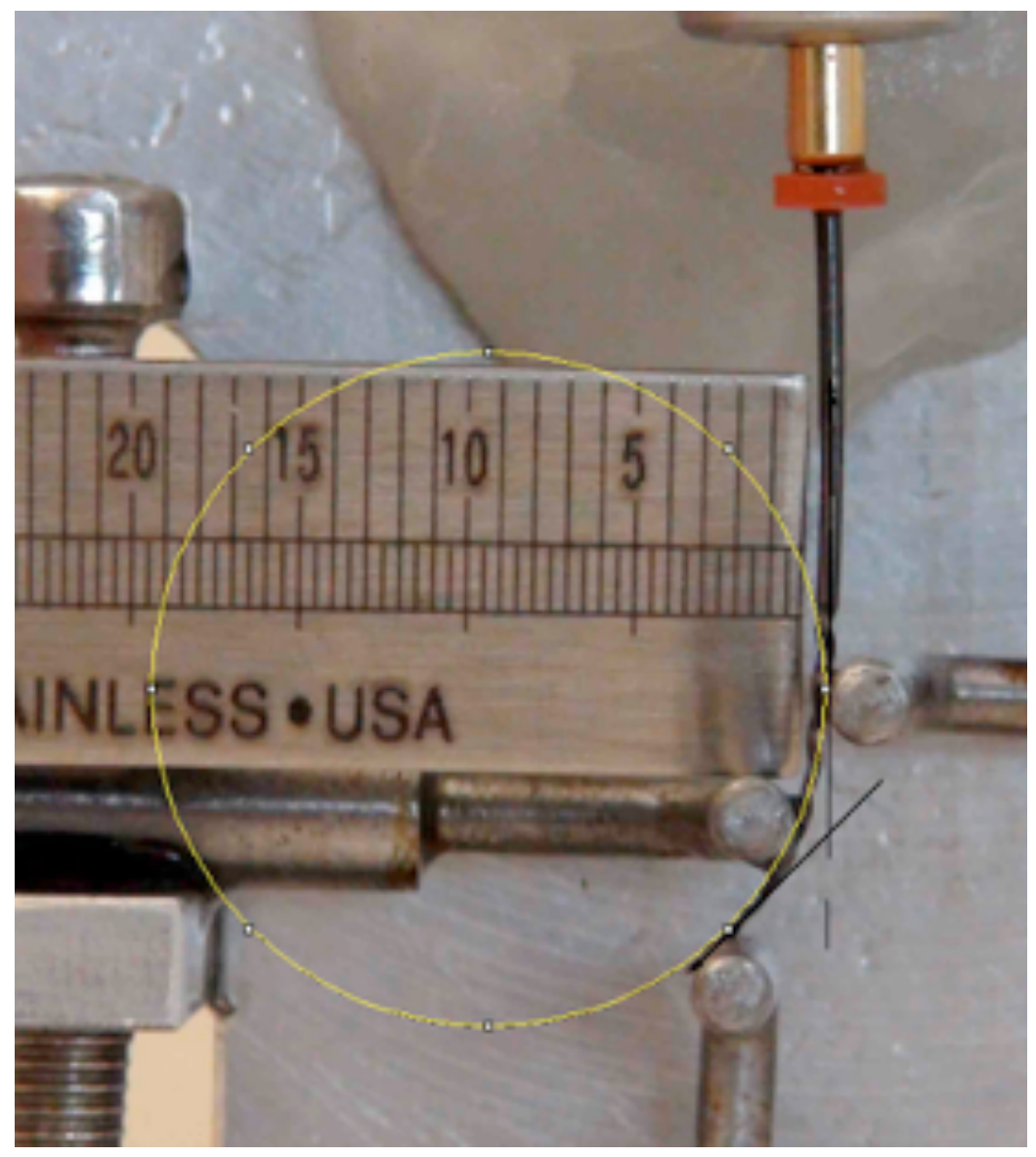

Figure 4.4. Drawing the arc prior to measurement. 
Once the arc had been created, the angle was determined using the software. The distance of the radius was determined by the use of the ruler in the calibrated photograph, as demonstrated in Figure 4.5.

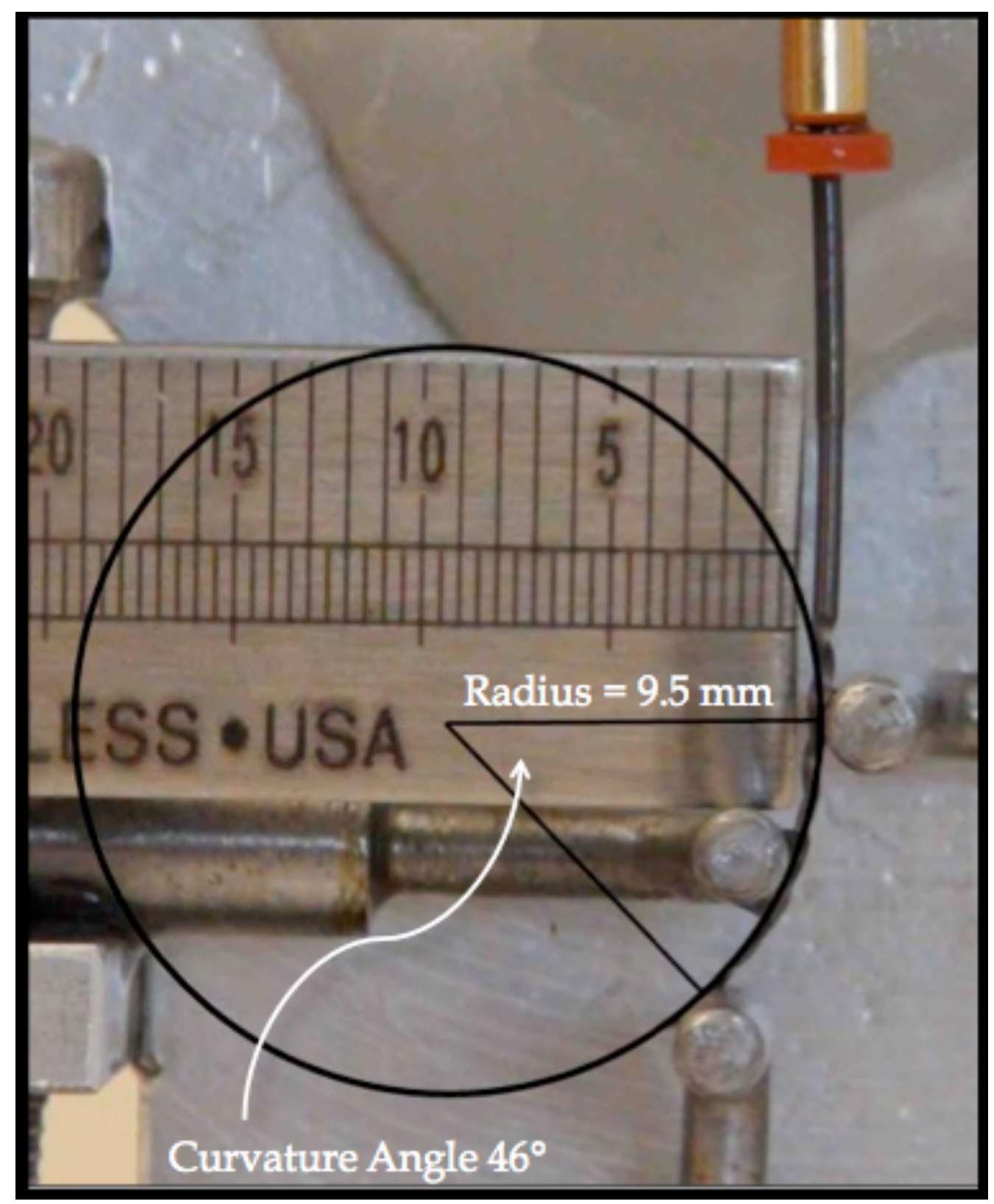

Figure 4.5. Calculation of radius and curvature angle. 


\subsection{Torsion Testing}

The files from each group had their handles removed to facilitate testing in the torsiometer by the use of crimping pliers. The handles of Typhoon files used in this experiment were glued on at time of their manufacture, so one option to remove the handle was the use of a flame, that could be used to soften the glue as demonstrated in Figure 4.6. However, the handle could more simply be cut from the file with crimping pliers prior to insertion in the torsiometer.

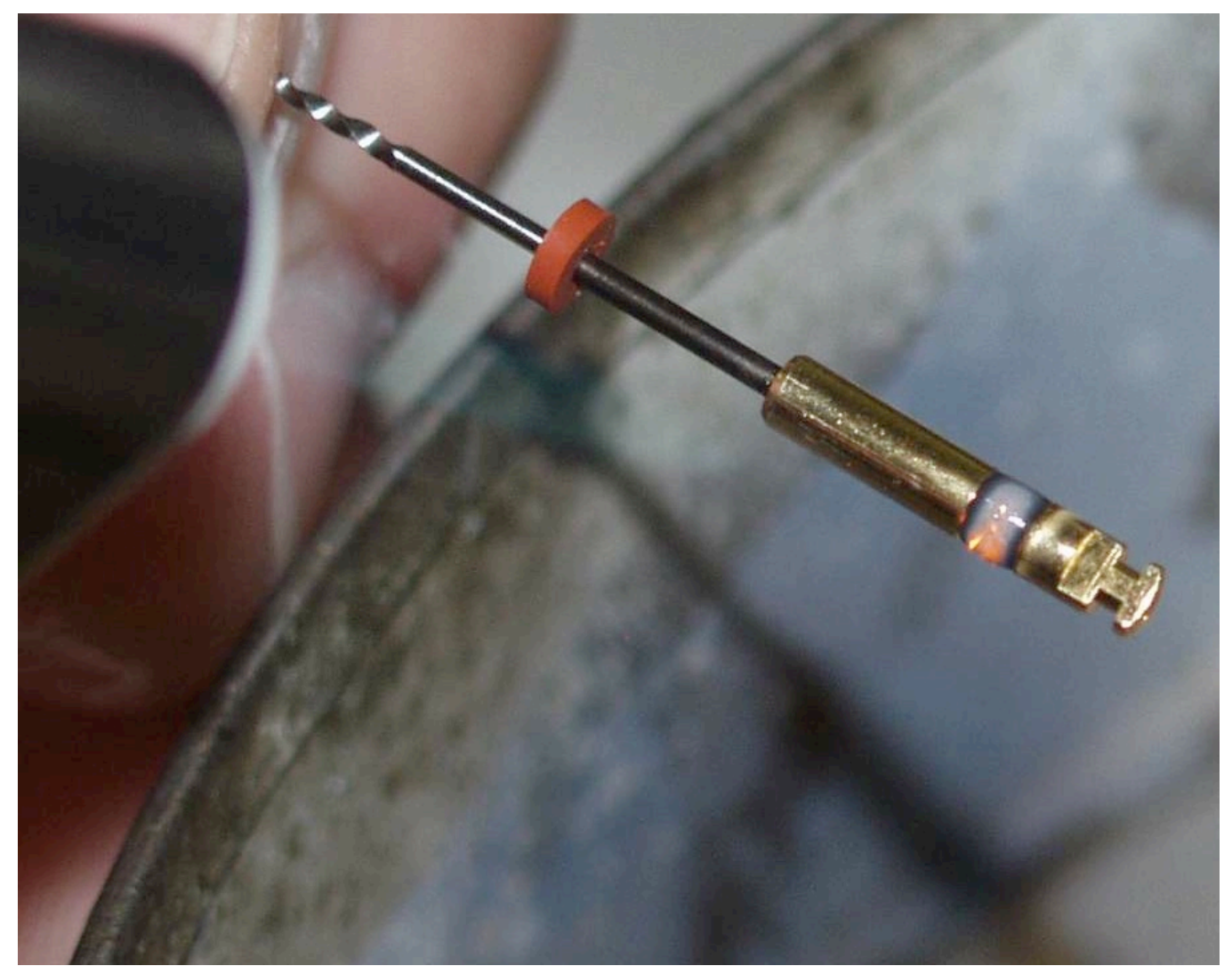

Figure 4.6. Removal of a file handle prior to a torsion test. 
The subsequent groups of previously cyclically preloaded files were exposed to torsional loading tests, with the exception of one group that was not precycled and considered to be the control group. The torque tests were performed in a torsion tester (also known as a torsiometer) until rupture to establish each file's mean value of torque to failure and maximum angular deflection of each group (Lopes et al., 2013). The torsion tests were performed based on International Organization for Standardization ISO 3630-1 (ISO3630-1, 2008) using a torsion machine. The rotation speed was set clockwise to two revolutions per minute (RPM). The end of the shaft was clamped into a chuck connected to a reversible geared motor. Three millimeters of the instrument's tip were clamped in another chuck with brass jaws to prevent sliding. The torsional load and distortion angle were recorded until the file separated.

\subsection{Fractographic Examination}

The fracture surfaces of all fragments were examined under a scanning electron microscope (SEM; Stereoscan 260; Cambridge Instruments, Cambridge, UK). The region in which the dimple area could be found was outlined on the photomicrograph for fatigue failure groups, and measured with Image $1.4 \mathrm{~g}$ software (National Institutes of Health, Bethesda, MD) on each photomicrograph. 


\subsection{Statistical Analysis}

The results were analyzed by using one-way ANOVA with post hoc analysis (SPSS for Windows 11.0, SPSS, Chicago, IL) at a significance level of $P<.05$. 


\section{Chapter 5. Results}

Within a water environment, both sizes 25.04 and 40.04 TYP CM instruments had a significantly higher number of revolutions in fatigue testing when compared to conventional nickel-titanium instruments $(P<.05)$. Table 5.1 represents the cyclical fatigue life of 25.04 and 40.04, both in NiTi and CM.

In size 25.04, there was no difference in torque between the CM files and the conventional NiTi files (Table 5.2) $(P>.05)$. The torque of size 40.04 files was significantly higher than the torque of size 25.04 files $(P<0.05)$. There was no significant difference of torque value TYP CM and TYP instruments of size 25.04 between precycling and no precycling groups.

In the 40.04 TYP group, the $75 \%$ pre-cycling group had a significantly lower torque than the no precycling group $(P<.05)$. In the TYP CM 40.04 group, the preloading groups $(25 \%, 50 \%$ and $75 \%)$ had a smaller distortion angle until fracture than the no preloading group $(P<.05)$.

The CM files of both sizes had a significantly higher distortion angle than conventional NiTi files of both sizes $(P<.05)$. The mean and standard deviation were calculated as indicated in Tables 5.1, 5.2 and 5.3. 
Table 5.1 The number of revolutions until fracture of Typhoon NiTi and CM files at a curvature $46^{\circ}$ with a $9.5 \mathrm{~mm}$ radius in a water environment (mean \pm S.D.)

\begin{tabular}{|l|l|l|}
\hline Brands & Size 25/.04* & Size 40/.04* \\
\hline Typhoon NiTi\& & $579 \pm 119$ & $320 \pm 52$ \\
Typhoon CM\& & $3968 \pm 632$ & $2143 \pm 307$ \\
\hline
\end{tabular}

* There was a statistically significant difference between the file sizes $(p<0.05)$. \& There was a statistically significant difference between the CM and NiTi files $(p<0.05)$. 
Table 5.2 (a) Torque and distortion angle at fracture by torque of 25.04 Typhoon $\mathrm{NiTi}$ and CM files fatigued $0-75 \%$ of the number of rotations to failure by fatigue (mean \pm S.D.)

\begin{tabular}{|c|c|c|c|c|c|c|}
\hline \multirow[b]{3}{*}{$\begin{array}{l}\text { Cyclic } \\
\text { pre- } \\
\text { cycling of } \\
\text { mNCF }\end{array}$} & \multicolumn{6}{|c|}{ Size 25.04} \\
\hline & \multicolumn{3}{|c|}{ Typhoon CM } & \multicolumn{3}{|c|}{ Typhoon NiTi } \\
\hline & $\mathrm{mNCF}$ & $\begin{array}{l}\text { Torque } \\
(\mathrm{N} \cdot \mathrm{mm})\end{array}$ & $\begin{array}{l}\text { Distortion } \\
\text { Angle }^{*} \\
\left.{ }^{\circ}\right)\end{array}$ & $\mathrm{mNCF}$ & $\begin{array}{l}\text { Torque } \\
(\mathrm{N} \cdot \mathrm{mm})\end{array}$ & $\begin{array}{l}\text { Distortion } \\
\text { Angle }^{*} \\
\left({ }^{\circ}\right)\end{array}$ \\
\hline 0 & 0 & $3.85 \pm 0.47$ & $792 \pm 50$ & 0 & $3.63 \pm 0.89$ & $500 \pm 61$ \\
\hline $25 \%$ & 992 & $3.56 \pm 0.40$ & $743 \pm 58$ & 147 & $3.30 \pm 0.33$ & $486 \pm 39$ \\
\hline $50 \%$ & 1984 & $3.36 \pm 0.35$ & $747 \pm 75$ & 290 & $3.44 \pm 0.36$ & $479 \pm 36$ \\
\hline $75 \%$ & 2976 & $3.33 \pm 0.66$ & $778 \pm 93$ & 434 & $3.48 \pm 0.44$ & $482 \pm 25$ \\
\hline
\end{tabular}

mNCF: the total number of revolutions to failure.

* There was a statistically significant difference between in distortion angle between the CM and NiTi files $(P<0.05)$. 
Table 5.2 (b) Resistance to torque of 40.04 Typhoon NiTi and CM files after cyclic precycling of the $\mathrm{mNCF}$

\begin{tabular}{|c|c|c|c|c|c|c|}
\hline \multirow[b]{3}{*}{$\begin{array}{l}\text { Cyclic } \\
\text { pre- } \\
\text { cycling } \\
\text { of } \\
\text { mNCF }\end{array}$} & \multicolumn{6}{|c|}{ Size 40.04} \\
\hline & \multicolumn{3}{|c|}{ Typhoon CM } & \multicolumn{3}{|c|}{ Typhoon NiTi } \\
\hline & $\mathrm{mNCF}$ & $\begin{array}{l}\text { Torque } \\
(\mathrm{N} \cdot \mathrm{mm})\end{array}$ & $\begin{array}{l}\text { Distortion } \\
\text { Angle }^{*} \\
\left(^{\circ}\right)\end{array}$ & $\mathrm{mNCF}$ & $\begin{array}{l}\text { Torque } \\
(\mathrm{N} \cdot \mathrm{mm})\end{array}$ & $\begin{array}{l}\text { Distortion } \\
\text { Angle }^{*} \\
\left({ }^{\circ}\right)\end{array}$ \\
\hline 0 & 0 & $11.29 \pm 0.78$ & $924 \pm 108^{\alpha}$ & 0 & $13.38 \pm 2.60^{\&}$ & $412 \pm 37$ \\
\hline $25 \%$ & 536 & $12.16 \pm 1.14$ & $750 \pm 60^{ß}$ & 80 & $12.12 \pm 1.59$ & $430 \pm 44$ \\
\hline $50 \%$ & 1072 & $12.13 \pm 1.11$ & $738 \pm 106^{\circledR}$ & 160 & $12.43 \pm 1.38$ & $417 \pm 36$ \\
\hline $75 \%$ & 1608 & $11.26 \pm 1.52$ & $712 \pm 109^{\beta}$ & 240 & $10.63 \pm 1.38 \&$ & $447 \pm 44$ \\
\hline
\end{tabular}

mNCF: the total number of revolutions to failure;

* There was a statistically significant difference in distortion angle between the CM and NiTi files $(P<0.05)$.

\& There was a statistically significant difference in torque of 40.04 NiTi files between no cyclic precycling of the $m N C F$ and $75 \%$ cyclic precycling of the $m N C F(P<0.05)$. $\alpha, \beta$ There was a statistically significant difference in distortion angle in CM files between those that were not precycled and those that were precycled. No difference was found within the CM precycled files, regardless if they were precycled to $25 \%, 50 \%$ or $75 \%$. 
Table 5.3 Time to failure by cyclic fatigue in a water environment at $9.5 \mathrm{~mm}$ radius and $46^{\circ}$ curvature (mean \pm S.D.)

\begin{tabular}{|l|l|l|}
\hline Brands & Size 25/.04* & Size 40/.04* \\
\hline Typhoon NiTi\& $1 \mathrm{~min} 9 \mathrm{sec} \pm 14 \mathrm{sec}$ & $38 \mathrm{sec} \pm 6 \mathrm{sec}$ \\
Typhoon CM\& & $7 \mathrm{~min} 56 \mathrm{sec} \pm 1 \mathrm{~min} 16 \mathrm{sec}$ & $4 \mathrm{~min} 16 \mathrm{sec} \pm 37 \mathrm{sec}$ \\
\hline
\end{tabular}

* There was a statistically significant difference between the file sizes ( $p<0.05)$. \& There was a statistically significant difference between the CM and NiTi files $(p<0.05)$. 
Fractographically, the images represent different patterns that were largely dependent on the composition of the file. Typically, the files made from CM wire had a much smaller dimpled area displayed through the scanning electron microscope. TYP CM instruments had a higher number of crack origins than TYP files in fatigue failure groups only (Figure 5.1). The values of the area occupied by the dimple region as part of the total surface area of the fractured cross-section were smaller on TYP CM instruments (Figure 5.1A) than on TYP instruments (Figure 5.1B) in only the fatigue failure groups. This was evident in both file sizes. The appearances of the fractured surface after the torsion test all exhibited the typical pattern of torsional fracture characterized by circular abrasion marks and skewed dimples near the center of rotation (Figure 5.1C-F).

A closer image in Figure 5.2 A and B is the same 25.04 NiTi file at $100 \%$ fatigue. Figure 5.2 A shows the fractured file while Figure 5.2 B shows the delineation of the dimpled as opposed to the non-dimpled area. Note that a dimpled area represents the majority of the area in this cross section view of the NiTi file. Figure 5.3 is a conventional NiTi 40.04 file that has a dimpled area quite similar to that shown in Figure 5.3B, with the majority of the file displaying dimples. In Figure 5.4, a 40.04 CM file is shown that has a much less dimpled area than the same sized conventional NiTi files. The images selected for these figures are typical and representative from those of their group. 

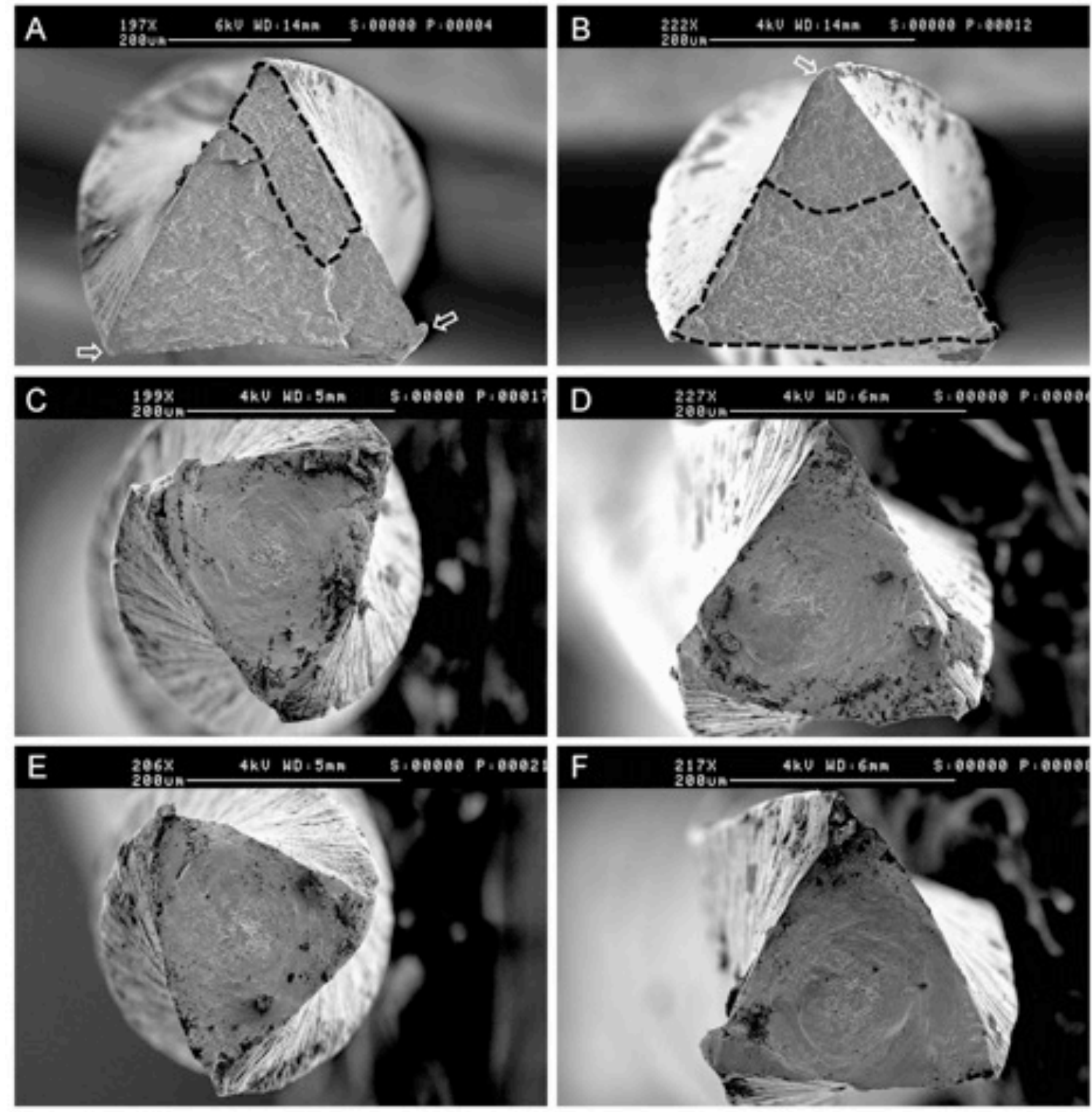

Figure 5.1. A photomicrograph of a fracture surface of (A) Typhoon CM instrument, and (B) Typhoon instrument with the region of fatigue crack propagation and dimple area outlined (dotted line) with crack origins (arrows) in fatigue test; (C)

Typhoon CM instrument, and (D) Typhoon instrument in torsion test without preloaded group; the 75\% cyclically preloaded of (E) Typhoon CM instrument, and

(F) Typhoon instrument in torsion test. 

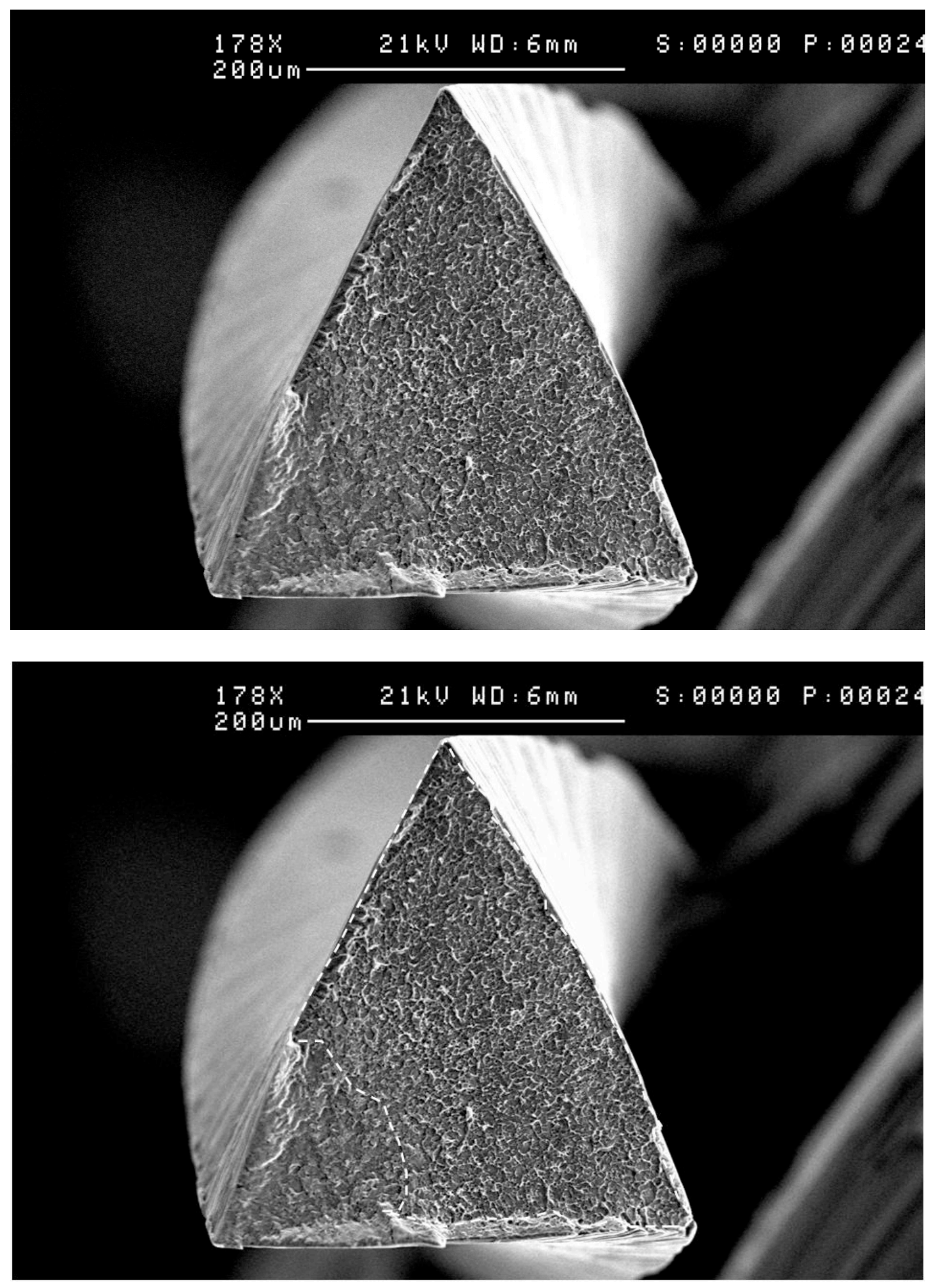

Figure 5.2. Demonstration of conventional NiTi before (above) and after outlining

(below) of dimpled area. 


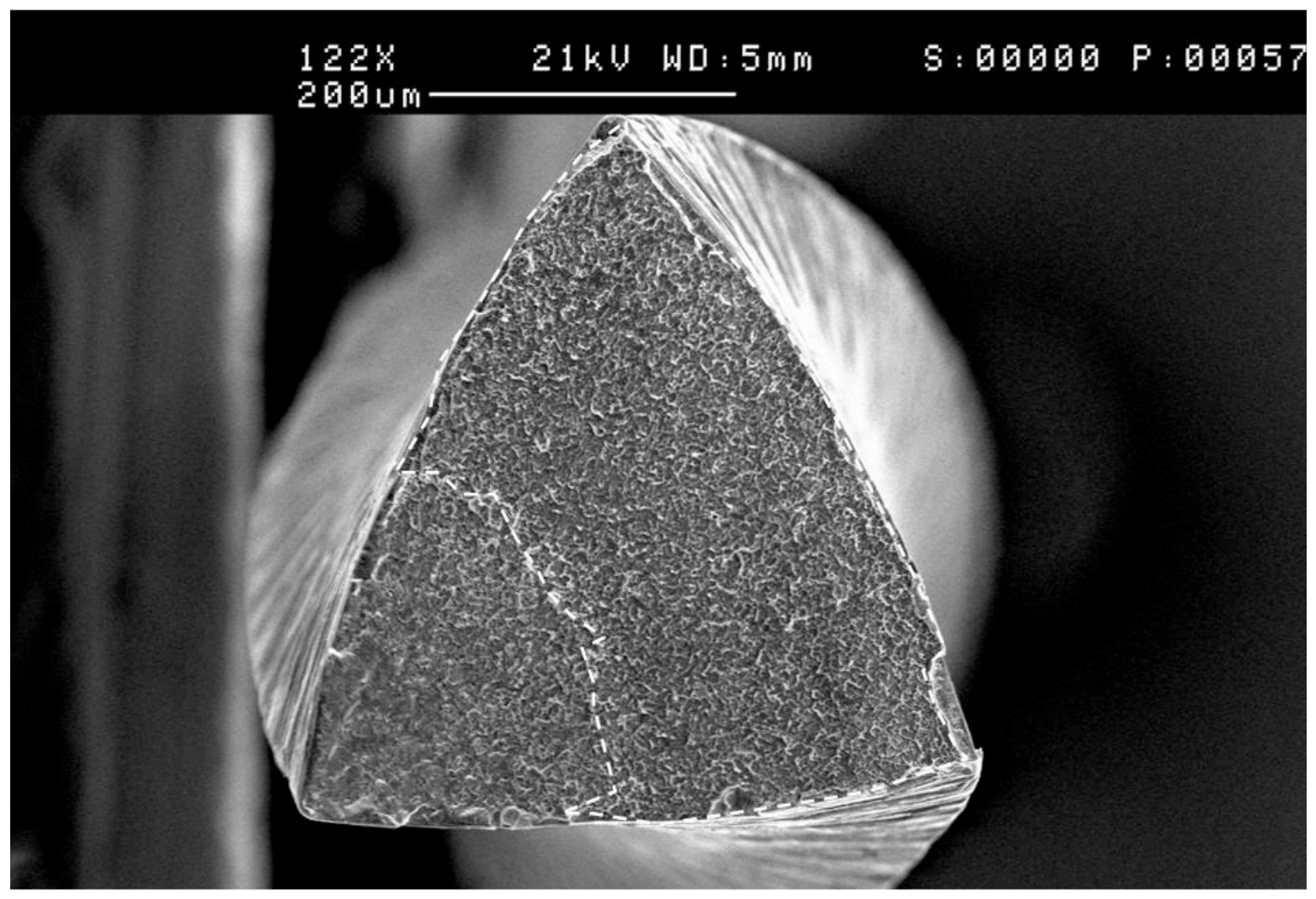

Figure 5.3. 40.04 NiTi dimpled area demonstration. The dimpled area represents the majority of the area in this cross-sectional view, which lie within the boundaries of the dotted line. 


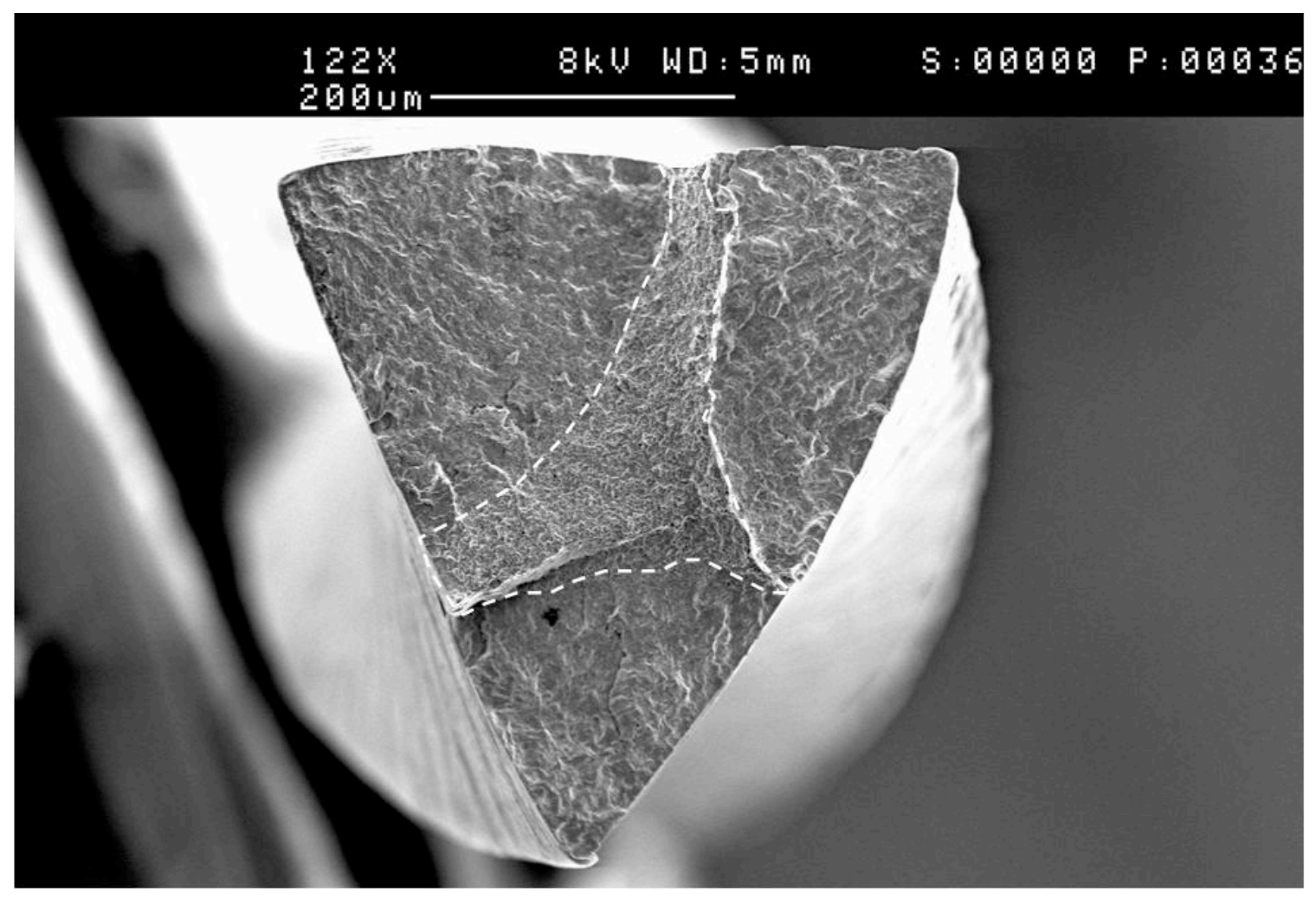

Figure 5.4. Demonstration of 40.04 CM dimpled area.

Note that the crack origins are from each point of the triangle in this sample. 


\section{Chapter 6. Discussion}

The aim of this study was to provide deep insight into the effect of cyclic fatigue on torsional failure of Typhoon CM instruments by varying the amount of cyclic preloading. Cyclic fatigue of NiTi rotary instruments has been studied extensively under simulated conditions (Chan \& Cheung, 1996; Plotino et al., 2009). The fatigue resistance of TYP CM files has been evaluated as an isolated process. The literature has limited information about torsional resistance of thermomechanically treated files, and very little specifically about TYP CM files. The torsional property of another CM instrument, Coltene Hyflex CM (Coltene Whaledent, Cuyahoga Falls, $\mathrm{OH}$ ), manufactured from a similar alloy has been recently reported (Pettiette et al., 2001; Peters et al., 2012). It is also known that rotary instruments experience both cyclic fatigue and torsional stress simultaneously when actively cutting dentin in curved canals (Blum et al., 1999; Cheung and Liu, 2009).

There is a scarcity of reports that examine the combined effect of these two factors for instrument fracture. In the present study, the torsional tests were performed on the third millimeter from the instrument's tip based on the position of the files that were previously submitted to the maximum curvature during flexural fatigue tests. When flexural fatigue and torsion were combined, these effects occurred at the same segment of the file. It should be emphasized, however, that the 
complexity of the clinical situation cannot be fully reproduced in vitro. Regardless, the test method in the present study may be one step closer to a more comprehensive representation of clinical conditions.

Thermomechanical processing is a frequently used method to optimize the microstructure and transformation behavior of NiTi alloys, which in turn have great influence on the reliability and mechanical properties of NiTi files (Pruett et al., 1997; Zuolo and Walton, 1997; Arens et al., 2003; Hou et al., 2011; Shen et al., 2011b; Zhou et al., 2012). Typhoon CM rotary instruments were recently characterized by an austenitic finish temperature of approximately $55^{\circ} \mathrm{C}$, indicating that at body temperature, the instrument would contain a significant proportion of martensitic alloy (Pruett et al., 1997; Parashos et al., 2004; Cheung et al., 2005; Shen et al., 2009b; Gao et al., 2010; Shen et al., 2011b). The martensitic form of NiTi has high resistance to fatigue. Therefore, it was not surprising that TYP CM instruments were more resistant to cyclic fatigue than the TYP instruments in both air and aqueous media (Sattapan et al., 2000a; Shen et al., 2011a) (Haïkel et al., 1999; Shen et al., 2006; 2012). This was also confirmed by the present findings in an aqueous media. As a general rule, flexible instruments have been assumed to be less resistant to torsional load (Pruett et al., 1997; Sattapan et al., 2000a; Kramkowski and Bahcall, 2009; Larsen et al., 2009; Alapati et al., 2009a; Gao et al., 2010; Gambarini et al., 2011; Kim et al., 2012; Wycoff and Berzins, 2012; Ye and Gao, 2012; Lopes et al., 2013). Torsional strength is related to how much a file can twist before fracture and is a desirable property during the preparation of narrow and 
constricted canals, as most typically this is when the file is subjected to high torsional loads. In the present study, TYP CM files without cyclic preloading had similar torque values than instruments made of conventional NiTi. For the angle of rotation before fracture, the TYP CM files without cyclic preloading generally possessed high values that were superior to the conventional TYP files. In this study, torque at failure was determined according to ISO3630-1, specifically those torque values that were sufficient to break the instrument at D3 when rotated with two rpm. However, clinical torque stresses occur at higher revolutions per minute, and file binding effects are influenced by canal anatomy, operator skill level, and other factors (Blum et al., 1999; Parashos et al., 2004). Therefore, the data obtained here cannot be directly extrapolated to clinical conditions and conclusions from the present study must be drawn with caution.

Previous studies showed that cyclic fatigue had a significant effect on torsional fracture resistance on ProFile and ProTaper instruments (Bahia and Dias, 2006; Kim et al., 2012). Particularly, instruments cycled to $75 \%$ of fatigue life had a significant decrease in their torsional resistance. In the present study, cyclic fatigue was not detrimental to the file's ability to withstand the torsional load of TYP and TYP CM files on size 25.04. In the larger size (40.04), the $75 \%$ preloading TYP instruments had reduced torsional strength; in the 25.04 group this was not the case and furthermore precycling of 25.04 TYP CM instruments showed a slight reduction in the instrument's distortion angle when compared to the no precycling group. However, in the clinical situation, there is no simple way to estimate the amount of 
cyclic fatigue accumulated in those multiple-use instruments. Interestingly, in both sizes, TYP CM files displayed a similar torque value to TYP files but rotated at a greater angle before fracturing in both the preloading and no preloading groups. In size 40.04 the angle of distortion was significantly less in the precycled groups when compared to the no precycling group, however the torque was not significantly different. Nevertheless, a high angle of rotation before fracture in TYP CM files may be beneficial because it may provide clinicians with an indication of plastic/permanent deformation. The clinician may consider it a warning that the ultimate yield strength of the metal may be approaching and that fracture may be imminent. Even though the total number of rotations of TYP CM instruments with the $75 \%$ preloading group was significantly higher than TYP instruments in the no precycling group, the torsional resistance of TYP CM instruments were similar to TYP instruments.

Parashos et al. (2004) found cyclic fatigue to be the more common mechanism of file fracture in clinical practice. Sattapan et al (2000a) conversely found that torsional stress was slightly more prevalent as the cause of fracture. In clinical practice, files can fracture as a result of either mechanism, often with little to no warning. Examination of the fracture surface at high magnification using scanning electron microscopy is essential to reveal features that may indicate the possible origin of cracks and the mode of material failure (Shen et al., 2009a). As previously discussed, cyclic fatigue fracture is characterized by numerous patches of linear fatigue-striation marks and torsional failure is characterized by circular 
abrasion marks on the fracture surface. CM files had fatigue resistance superior to files made from conventional NiTi alloy. Hence, it is not surprising that the values of the area occupied by the dimple region as part of the total surface area of the fracture cross-section were significantly smaller on instruments made from CM wire than on instruments made from conventional NiTi wire in the cyclic fatigue test (Shen et al., 2011a; 2012). Their findings lend support to the results obtained here. The patterns established in this study for the fractured files supply a consistent base for the interpretation of fracture occurring under complex loading. The results showed that in the case of both heat-treated NiTi instruments and conventional superelastic NiTi instruments in which the torsional test was applied after an incomplete flexural fatigue test, the fractography corresponded to the torsional fracture pattern. These data are in accordance with previous studies (Kim et al., 2012) that found the fractured conventional NiTi files after torsional tests showed typical features of torsional failure; there was little difference with regard to the brands or amount of precycling. From a clinical point of view, the results of this investigation also allow for speculation that an instrument fracture may be a result of a combination of cyclic fatigue and torsional load, although the fractographic examination reveals that an instrument fails from torsional fracture. The information from the foregoing case will aid clinicians in their understanding of the fracture process under clinical conditions. Further research is recommended for examining the effect of torsional fatigue on the cyclic fatigue fracture of NiTi CM files. 


\section{Chapter 7. Conclusions}

CM files behaved differently in a test environment than conventional NiTi rotary files. The present findings indicate that the fatigue life of CM instruments is significantly longer than conventional superelastic NiTi instruments. During cyclic testing to failure, CM files did not always fracture all the way through; sometimes the three millimeter tip of the file remained connected to the rest of the file as it rotated in the three-point bending apparatus, similar to an upside down helicopter. It is theorized that this is because a high portion of the file is of martensitic composition at testing temperatures.

TYP CM files displayed a torque resistance similar to TYP files but rotated a greater amount angle before fracture in the preloading and no preloading groups. It was not uncommon during torsion testing to observe the file unwind and then rewind on itself multiple times before fracture. There was no significant difference of torque value and distortion angle on both TYP CM and TYP instruments of size 25.04 between the precycling and no precycling groups. Cyclic fatigue had an effect on torsional fracture resistance in size 40.04 . Moreover, when 40.04 was precycled to $75 \%$ of their cyclic fatigue life, TYP instruments showed a reduction in their torsional resistance compared with the no precycling group; precycling of TYP CM instruments reduced the distortion angle. 
It is possible that precycling files prior to torque testing to an amount greater than $75 \%$ would show interesting fractographic combination patterns. The problem this presents is that as the mean cyclical failure rate is approached, more samples would be lost prior to torsional testing.

Thermo-mechanically treated files are the latest generation of endodontic rotary systems. Within the limitations of this study, TYP files appear to significantly increase their fatigue performance with generally no loss of torsional strength. This should be of benefit to the daily routine of the clinician, since it is in this situation that it matters most. 


\section{References}

Al-Fouzan KS. Incidence of rotary ProFile instrument fracture and the potential for bypassing in-vivo. Int Endod J. 2003;36(12):864-7.

Alapati SB, Brantley WA, Iijima M, Clark WAT, Kovarik L, Buie C, Liu J, Johnson WB. Metallurgical characterization of a new nickel-titanium wire for rotary endodontic instruments. J Endod. 2009a;35(11):1589-93.

Alapati SB, Brantley WA, Iijima M, Schricker SR, Nusstein JM, Li U-M, Svec T. MicroXRD and temperature-modulated DSC investigation of nickel-titanium rotary endodontic instruments. Dent Mater. 2009b;25(10):1221-9.

Anderson ME, Price JWH, Parashos P. Fracture resistance of electropolished rotary nickel-titanium endodontic instruments. J Endod. 2007;33(10):1212-6.

Arens F, Hoen M, Steiman H, Dietzjr G. Evaluation of single-use rotary nickeltitanium instruments. J Endod. 2003;29(10):664-6.

Atkinson HV, Shi G. Characterization of inclusions in clean steels: a review including the statistics of extremes methods. Progress in Materials Science. Elsevier; 2003;48(5):457-520.

Baek S-H, Lee C-J, Versluis A, Kim B-M, Lee W, Kim H-C. Comparison of torsional stiffness of nickel-titanium rotary files with different geometric characteristics. J Endod. 2011;37(9):1283-6. 
Bahia MG de A, Dias RF. The influence of high amplitude cyclic straining on the behaviour of superelastic NiTi. Int J Fatigue. 2006;28:1087-91.

Barbosa FOG, Gomes JADCP, de Araújo MCP. Influence of electrochemical polishing on the mechanical properties of K3 nickel-titanium rotary instruments. J Endod. 2008;34(12):1533-6.

Best S, Watson P, Pilliar R, Kulkarni GGK, Yared G. Torsional fatigue and endurance limit of a size 30.06 ProFile rotary instrument. Int Endod J. 2004;37(6):370-3.

Bhagabati N, Yadav S, Talwar S. An in vitro cyclic fatigue analysis of different endodontic nickel-titanium rotary instruments. J Endod. 2012;38(4):515-8.

Bishop K, Dummer PMH. A comparison of stainless steel flexofiles and nickeltitanium nitiFlex files during the shaping of simulated canals. Int Endod J. 1997;30(1):25-34.

Blum JY, Machtou P, Micallef JP. Location of contact areas on rotary Profile instruments in relationship to the forces developed during mechanical preparation on extracted teeth. Int Endod J. 1999;32(2):108-14.

Brantley W, Svec T, Iijima M, Powers J, Grentzer T. Differential scanning calorimetric studies of nickel titanium rotary endodontic instruments. J Endod. 2002;28(8):567-72.

Buehler WJ, Gilfrich JV, Wiley RC. Effect of low-temperature phase changes on the mechanical properties of alloys near composition TiNi. J. Appl. Phys. 
1963;34(5):1475.

Buehler WJ, Wang FE. A summary of recent research on the nitinol alloys and their potential application in ocean engineering. Ocean Engineering. 1968;1:105-20.

Casper RB, Roberts HW, Roberts MD, Himel VT, Bergeron BE. Comparison of autoclaving effects on torsional deformation and fracture resistance of three innovative endodontic file systems. J Endod. Elsevier Ltd; 2011;37(11):1572-5.

Chan AWK, Cheung GSP. A comparison of stainless steel and nickel-titanium K-files in curved root canals. Int Endod J. 1996;29(6):370-5.

Cheung G, Darvell BW. Fatigue testing of a NiTi rotary instrument. Part 1: strain-life relationship. Int Endod J. 2007;40(8):612-18.

Cheung G, Liu C. A retrospective study of endodontic treatment outcome between nickel-titanium rotary and stainless steel hand filing techniques. J Endod. 2009;35(7):938-43.

Cheung GSP. Instrument fracture: mechanisms, removal of fragments, and clinical outcomes. Endodontic Topics. 2009;16:1-26.

Cheung GSP, Peng B, Bian Z, Shen Y, Darvell BW. Defects in ProTaper S1 instruments after clinical use: fractographic examination. Int Endod J. 2005;38(11):802-9.

Crump MC, Natkin E. Relationship of broken root canal instruments to endodontic case prognosis: a clinical investigation. J Am Dent Assoc. 1970;80(6):1341-7. 
Dederich DN, Zakariasen KL. The effects of cyclical axial motion on rotary endodontic instrument fatigue. Oral Surgery, Oral Medicine, Oral Pathology. 1986;61(2):192-6.

DS Dental press release. 2010.

Esposito PT, Cunningham CJ. A comparison of canal preparation with nickeltitanium and stainless steel instruments. J Endod. 1995;21(4):173-6.

Gambarini G, Plotino G, Grande NM, Al-Sudani D, De Luca M, Testarelli L. Mechanical properties of nickel-titanium rotary instruments produced with a new manufacturing technique. Int Endod J. 2011;44(4):337-41.

Gao Y, Shotton V, Wilkinson K, Phillips G. Effects of raw material and rotational speed on the cyclic fatigue of ProFile Vortex rotary instruments. J Endod. 2010;36(7):1205-9.

Haïkel Y, Serfaty R, Bateman G, Senger B, Allemann C. Dynamic and cyclic fatigue of engine-driven rotary nickel-titanium endodontic instruments. J Endod. 1999;25(6):434-40.

Hou XM, Yahata Y, Hayashi Y, Ebihara A, Hanawa T, Suda H. Phase transformation behaviour and bending property of twisted nickel-titanium endodontic instruments. Int Endod J. 2011;44(3):253-8.

IS03630-1. Dentistry - Root-canal instruments. International Organization for Standardization. 2nd ed. 2008;1-26. 
Kim J-Y, Shun-Pan Cheung G, Park S-H, Ko D-C, Kim J-W, Kim H-C. Effect from cyclic fatigue of nickel-titanium rotary files on torsional resistance. J Endod. 2012;38(4):527-30.

Kitchens GG Jr, Liewehr FR, Moon PC. The effect of operational speed on the fracture of nickel-titanium rotary instruments. J Endod. 2007;33(1):52-4.

Kramkowski TR, Bahcall J. An In Vitro comparison of torsional stress and cyclic fatigue resistance of ProFile GT and ProFile GT Series X rotary nickel-titanium files. J Endod. 2009;35(3):404-7.

Larsen CM, Watanabe I, Glickman GN, He J. Cyclic fatigue analysis of a new generation of nickel titanium rotary instruments. J Endod. 2009;35(3):401-3.

Li U, Lee B, Shih C, Lan W, Lin C. Cyclic fatigue of endodontic nickel titanium rotary instruments: static and dynamic tests. J Endod. 2002;28(6):448-51.

Lopes HP, Gambarra-Soares T, Elias CN, Siqueira JF, Inojosa IFJ, Lopes WSP, et al. Comparison of the mechanical properties of rotary instruments made of conventional nickel-titanium wire, M-wire, or nickel-titanium alloy in R-phase. J Endod. 2013;39(4):516-20.

McKelvey AL, Ritchie RO. Fatigue-crack propagation in Nitinol, a shape-memory and superelastic endovascular stent material. J. Biomed. Mater. Res. 1999 ;47(3):3018.

Mize SB, Clement DJ, Pruett JP, Carnes DL Jr. Effect of sterilization on cyclic fatigue of 
rotary nickel-titanium endodontic instruments. J Endod. 1998;24(12):843-7.

Ounsi HF, Salameh Z, Al-Shalan T, Ferrari M, Grandini S, Pashley DH, et al. Effect of clinical use on the cyclic fatigue resistance of ProTaper nickel-titanium rotary instruments. J Endod. 2007;33(6):737-41.

Parashos P, Gordon I, Messer H. Factors influencing defects of rotary nickel-titanium endodontic instruments after clinical use. J Endod. 2004;30(10):722-5.

Parashos P, Messer HH. Questionnaire survey on the use of rotary nickel-titanium endodontic instruments by Australian dentists. Int Endod J. 2004;37(4):249-59.

Park S-Y, Cheung GSP, Yum J, Hur B, Park J-K, Kim H-C. Dynamic torsional resistance of nickel-titanium rotary instruments. J Endod. 2010;36(7):1200-4.

Peng B, Shen Y, Cheung GSP, Xia TJ. Defects in ProTaper S1 instruments after clinical use: longitudinal examination. Int Endod J. 2005;38(8):550-7.

Peters OA, Gluskin AK, Weiss RA, Han JT. An in vitro assessment of the physical properties of novel Hyflex nickel-titanium rotary instruments. Int Endod J. 2012;45(11):1027-34.

Pettiette MT, Delano EO, Trope M. Evaluation of success rate of endodontic treatment performed by students with stainless-steel K-Files and nickeltitanium hand files. J Endod. 2001;27 (2):124-7.

Plotino G, Grande NM, Cordaro M, Gambarini G. A review of cyclic fatigue testing of nickel-Titanium Rotary Instruments. J Endod. Elsevier Ltd; 2009;35(11):1469- 
76.

Pruett JP, Clement DJ, Carnes DL. Cyclic fatigue testing of nickel-titanium endodontic instruments. J Endod. 1997;23(2):77-85.

Sattapan B, Nervo G, Palamara J, Messer H. Defects in rotary nickel-titanium files after clinical use. J Endod. 2000a;26(3):161-5.

Sattapan B, Palamara JE, Messer HH. Torque during canal instrumentation using rotary nickel-titanium files. J Endod. 2000b;26(3):156-60.

Schilder H. Cleaning and shaping the root canal. Dent. Clin. North Am. 1974;18(2):269-96.

Schneider SW. A comparison of canal preparations in straight and curved root canals. Oral Surgery, Oral Medicine, Oral Pathology. 1971;32(2):271-5.

Shen Y, Cheung GS-P, Bian Z, Peng B. Comparison of defects in ProFile and ProTaper systems after clinical use. J Endod. 2006;32(1):61-5.

Shen Y, Cheung GS-P, Peng B, Haapasalo M. Defects in nickel-titanium instruments after clinical use. Part 2: Fractographic analysis of fractured surface in a cohort study. J Endod. 2009a;35(1):133-6.

Shen Y, Haapasalo M, Cheung GS-P, Peng B. Defects in nickel-titanium instruments after clinical use. Part 1: Relationship between observed imperfections and factors leading to such defects in a cohort study. J Endod. 2009b;35(1):129-32. 
Shen Y, Qian W, Abtin H, Gao Y, Haapasalo M. Fatigue testing of controlled memory wire nickel-titanium rotary instruments. J Endod. 2011a;37(7):997-1001.

Shen Y, Qian W, Abtin H, Gao Y, Haapasalo M. Effect of environment on fatigue failure of controlled memory wire nickel-titanium rotary instruments. J Endod. 2012;38(3):376-80.

Shen Y, Zhou H-M, Wang Z, Campbell L, Zheng Y-F, Haapasalo M. Phase transformation behavior and mechanical properties of thermomechanically treated K3XF nickel-titanium instruments. J Endod. 2013a;39(7):919-23.

Shen Y, Zhou H-M, Zheng Y-F, Campbell L, Peng B, Haapasalo M. Metallurgical characterization of controlled memory wire nickel-titanium rotary instruments. J Endod. 2011b;37(11):1566-71.

Shen Y, Zhou H-M, Zheng Y-F, Peng B, Haapasalo M. Current challenges and concepts of the thermomechanical treatment of nickel-titanium instruments. J Endod. 2013b;39(2):163-72.

Siqueira TAG, Santos dos M, Siqueira EL, da Costa C, Nicoletti MA. Influence of irrigant viscosity on torsional fracture resistance of rotary nickel-titanium instruments. RGO. 2012;60(3):309-14.

Souter N, Messer H. Complications Associated with Fractured File Removal Using an Ultrasonic Technique. J Endod. 2005;31(6):450-2.

Spili P, Parashos P, Messer HH. The impact of instrument fracture on outcome of 
endodontic treatment. J Endod. 2005;31(12):845-50.

Testarelli L, Plotino G, Vincenzi V, Giansiracusa A, Grande NM, Gambarini G. Bending Properties of a New Nickel-Titanium Alloy with a Lower Percent by Weight of Nickel. J Endod. 2011;37(9):1293-5.

Thompson SA. An overview of nickel-titanium alloys used in dentistry. Int Endod J; 2001;33(4):297-310.

Walia H, Brantley WA, Gerstein H. An initial investigation of the bending and torsional properties of Nitinol root canal files. J Endod; 1988;14(7):346-51.

Wycoff RC, Berzins DW. An in vitro comparison of torsional stress properties of three different rotary nickel-titanium files with a similar cross-sectional design. J Endod. 2012;38(8):1118-20.

Yared G. In Vitro Study of the Torsional properties of new and used ProFile nickel titanium rotary files. J Endod. 2004;30(6):410-2.

Yared GM, Dagher FEB, Machtou P. Cyclic fatigue of Profile rotary instruments after simulated clinical use. Int Endod J. 1999;32(2):115-9.

Ye J, Gao Y. Metallurgical characterization of M-Wire nickel-titanium shape memory alloy used for endodontic rotary instruments during low-cycle fatigue. J Endod. 2012 Jan;38(1):105-7.

Yum J, Cheung GSP, Park J-K, Hur B, Kim H-C. Torsional strength and toughness of nickel-titanium rotary files. J Endod; 2011;37(3):382-6. 
Zhang E-W, Cheung GSP, Zheng Y-F. Influence of cross-sectional design and dimension on mechanical behavior of nickel-titanium instruments under torsion and bending: A numerical analysis. J Endod. 2010;36(8):1394-8.

Zhou H-M, Shen Y, Zheng W, Li L, Zheng Y-F, Haapasalo M. Mechanical properties of controlled memory and superelastic nickel-titanium wires used in the manufacture of rotary endodontic instruments. J Endod. 2012;38(11):1535-40.

Zinelis S, Darabara M, Takase T, Ogane K, Papadimitriou GD. The effect of thermal treatment on the resistance of nickel-titanium rotary files in cyclic fatigue. Oral Surg, Oral Med, Oral Path, Oral Rad, and Endo. 2007;103(6):843-7.

Zinelis S, Eliades T, Eliades G. A metallurgical characterization of ten endodontic niti instruments: assessing the clinical relevance of shape memory and superelastic properties of Ni-Ti endodontic instruments. Int Endod J. 2010;43(2):125-34.

Zuolo ML, Walton RE. Instrument deterioration with usage: nickel-titanium versus stainless steel. Quintessence Int. 1997;28(6):397-402. 